\title{
Electronic Structure of the Ferryl Intermediate in the $a$ - Ketoglutarate Dependent Non-Heme Iron Halogenase SyrB2: Contributions to H Atom Abstraction Reactivity
}

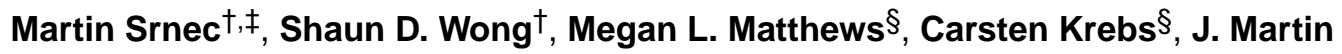 \\ Bollinger $\$$, and Edward I. Solomon ${ }^{*} \dagger$ \\ tDepartment of Chemistry, Stanford University, Stanford, California 94305-5080, United States \\ ¥J. Heyrovský Institute of Physical Chemistry, The Czech Academy of Sciences, Dolejškova \\ 2155/3, 18223 Prague 8, Czech Republic \\ $\S$ Department of Chemistry, Pennsylvania State University, University Park, Pennsylvania 16802, \\ United States
}

\begin{abstract}
Low temperature magnetic circular dichroism (LT MCD) spectroscopy in combination with quantum-chemical calculations are used to define the electronic structure associated with the geometric structure of the $\mathrm{Fe}^{\mathrm{IV}}=\mathrm{O}$ intermediate in $\mathrm{SyrB} 2$ that was previously determined by nuclear resonance vibrational spectroscopy. These studies elucidate key frontier molecular orbitals (FMOs) and their contribution to $\mathrm{H}$ atom abstraction reactivity. The VT MCD spectra of the enzymatic $S=2 \mathrm{Fe}^{\mathrm{IV}}=\mathrm{O}$ intermediate with $\mathrm{Br}^{-}$ligation contain information-rich features that largely parallel the corresponding spectra of the $S=2$ model complex $\left(\mathrm{TMG}_{3}\right.$ tren) $\mathrm{Fe}^{\mathrm{IV}}=\mathrm{O}$ (Srnec, M.; Wong, S. D.; England, J; Que, L; Solomon, E. I. Proc. Natl. Acad. Sci. USA 2012, $109,14326-14331)$. However, quantitative differences are observed that correlate with $\pi$ anisotropy and oxo donor strength that perturb FMOs and affect reactivity. Due to $\pi$-anisotropy, the $\mathrm{Fe}^{\mathrm{IV}}=\mathrm{O}$ active site exhibits enhanced reactivity in the direction of the substrate cavity that proceeds through a $\pi$-channel that is controlled by perpendicular orientation of the substrate $\mathrm{C}-\mathrm{H}$ bond relative to the halide- $\mathrm{Fe}^{\mathrm{IV}}=\mathrm{O}$ plane. Also, the increased intrinsic reactivity of the SyrB2 intermediate relative to the ferryl model complex is correlated to a higher oxyl character of the $\mathrm{Fe}^{\mathrm{IV}}=\mathrm{O}$ at the transition states resulting from the weaker ligand field of the halogenase.
\end{abstract}

"Corresponding Author: edward.solomon@stanford.edu.

Notes

The authors declare no competing financial interest

Supporting Information

The Supporting Information is available free of charge on the ACS Publications website at DOI: 10.1021/jacs.6b01151.

Figures showing (S1) DFT cluster model of the enzymatic intermediate and its truncation for multiconfigurational/multireference calculations, (S2) complete active space used in CASSCF/CASPT2 calculations, (S3) restricted active space in RASSCF calculations, (S4) temperature dependence of MCD spectral features, (S5) evolution of oxyl character along the Fe-O coordinate in two lowest excited states, (S6) potential energy curves of three lowest $S=2$ states and ten lowest $S=1$ states, (S7) calculated electronic spectra of the bromide vs chloride bound $\mathrm{Fe}{ }^{\mathrm{IV}}=\mathrm{O}$ intermediate, (S8) potential energy curves of the CT state of the $\mathrm{SyrB} 2 \mathrm{Br}-\mathrm{Fe}^{\mathrm{IV}} \mathrm{O}$ intermediate with the oxo group having 0,1 or 2 hydrogen bonds, and (S9) geometric and electronic structure parameters for transition states of $\mathrm{H}$ atom abstraction in both the enzymatic and synthetic systems; Table $\mathrm{S} 1$ comparing energetics for $\mathrm{H}$ atom abstraction; Cartesian coordinates of calculated structures (PDF) 


\section{Graphical abstract}

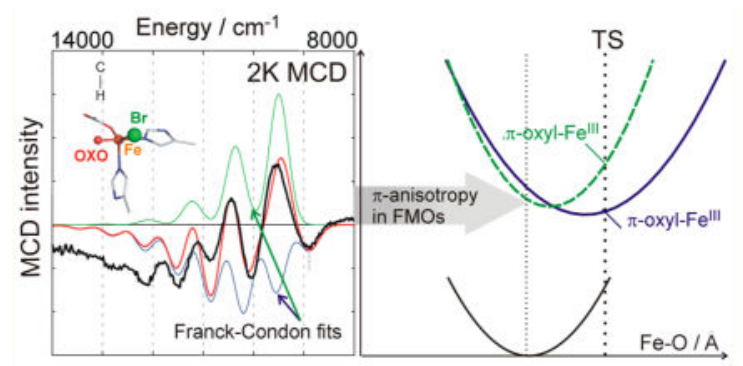

\section{INTRODUCTION}

Syringomycin halogenase ( $\mathrm{SyrB} 2)$ is a member of the mononuclear nonheme iron (NHFe) enzymes family that activates ${ }^{3} \mathrm{O}_{2}$, through formation of a key high-spin $(S=2) \mathrm{Fe}^{\mathrm{IV}}=\mathrm{O}$ intermediate, for $\mathrm{H}$ atom abstraction (HAA) from an unreactive $\mathrm{C}-\mathrm{H}$ bond to perform halogenation or hydroxylation. ${ }^{1}$ To date, six NHFe enzymatic $\mathrm{Fe}^{\mathrm{IV}}=\mathrm{O}$ intermediates have been trapped and spectroscopically characterized mostly by using Mössbauer spectroscopy, five of which are $a$-ketoglutarate ( $a \mathrm{KG}$ ) dependent (taurine dioxygenase (TauD), ${ }^{2,3}$ prolyl-4-hydroxylase $(\mathrm{P} 4 \mathrm{H}),{ }^{4}$ cytotrienin halogenase $(\mathrm{CytC} 3),{ }^{5,6}$ syringomicyn halogenase (SyrB2), ${ }^{1,7}$ carbapenem synthase $(\mathrm{CarC})^{8}$ ) and the other two are pterin dependent (tyrosine hydroxylase $(\mathrm{TyrH})^{9}$ and phenylalanine hydroxylase $(\mathrm{PheH})^{10}$ ). In the catalytic cycle of SyrB2, for which the substrate-free crystal structure from ref 11 is displayed in Figure 1A, the halide atom is incorporated into the methyl group of the L-threonine $\sim$ SyrB1 substrate (Figure 1B) in the biosynthesis of the phytotoxin syringomycin E. ${ }^{12}$

$\mathrm{NHFe}^{\mathrm{IV}}=\mathrm{O}$ enzyme intermediates have stimulated synthetic efforts to prepare $\mathrm{Fe}^{\mathrm{IV}}=\mathrm{O}$ compounds to elucidate crucial physicochemical factors that contribute to their reactivity in Nature. ${ }^{13}$ While most of the $\mathrm{Fe}^{\mathrm{IV}}=\mathrm{O}$ model complexes have low-spin $(S=1)$ ground states, ${ }^{14}$ some models have the $S=2$ spin state that is present in the enzymatic intermediates. ${ }^{15}$ A combined spectroscopic and computational study of one of the $S=2$ model complexes, $\left(\mathrm{TMG}_{3}\right.$ tren $) \mathrm{Fe}^{\mathrm{IV}}=\mathrm{O},{ }^{15 \mathrm{a}}$ elucidated three reactive channels available for HAA: two are active when the $\mathrm{C}-\mathrm{H}$ bond is oriented perpendicular to the $\mathrm{Fe}-\mathrm{oxo}$ bond ( $\pi$ channels leading to $S_{\mathrm{Fe}}=5 / 2$ or $S_{\mathrm{Fe}}=3 / 2 \mathrm{Fe}^{\mathrm{III}}-\mathrm{OH}$ intermediates) and one that is active for C-H bonds oriented along the Fe-oxo bond ( $\sigma$ channel providing an $S_{\mathrm{Fe}}{ }^{\mathrm{III}}=5 / 2$ intermediate). ${ }^{16}$ This is strikingly different from the $S=1 \mathrm{Fe}^{\mathrm{IV}}=\mathrm{O}$ complexes, which have only one available channel, $\pi\left(S_{\mathrm{Fe}}{ }^{\mathrm{III}}=3 / 2\right) .{ }^{17}$ Thus, $S=2$ active sites in NHFe enzymes have both $\pi$ and $\sigma$ channels providing flexibility in using different substrate orientations to control selectivity. ${ }^{18}$ Note that the $\sigma$ - and $\pi$-channels for HAA reactivity of $S=1$ and $S=2$ $\mathrm{NHFe}^{\mathrm{IV}}=\mathrm{O}$ systems are also discussed in ref 19.

Recently nuclear resonance vibrational spectroscopy (NRVS), correlated with density functional theory, allowed elucidation of the structure of the $\mathrm{Fe}^{\mathrm{IV}}=\mathrm{O}$ intermediate in SyrB2. ${ }^{20}$ This has a $5 \mathrm{C}$, trigonal bipyramidal (TBP) structure with the $\mathrm{Fe}-\mathrm{oxo}$ bond oriented along its $\sim C_{3}$ axis and perpendicular to the $\mathrm{C}-\mathrm{H}$ bond of the substrate. This had important 
implications for $\pi$-channel reactivity in controlling halogenation (see also Figure $1 \mathrm{C}$ and D). ${ }^{20}$

For the native L-threonine, L-Thr (and the alternative L-cyclopropylglycine, L-Cpg) substrate, this ferryl intermediate was shown to result from an $\mathrm{O}_{2}$ activation pathway that involves the two-electron reduction of dioxygen by the $a \mathrm{KG}$-bound $\mathrm{Fe}^{\mathrm{II}}$ center to generate an $S=1$ peroxy-bridged $a \mathrm{KG}$-bound $\mathrm{Fe}^{\mathrm{IV}}$ species that undergoes a subsequent two-electron reduction through an $S=1 \rightarrow S=2$ oxidative decarboxylation of the $a \mathrm{KG}$ cofactor $^{21}$ (summarized in Figure 1C). In the presence of the alternative substrate L-norvaline, L-Nva, the analogous $\mathrm{O}_{2}$ reaction pathway was proposed to lead to an $\mathrm{Fe}^{\mathrm{IV}}=\mathrm{O}$ intermediate now with its $\mathrm{Fe}$-oxo bond oriented toward the $\mathrm{C}-\mathrm{H}$ bond of the substrate. This led to $\sigma$-channel reactivity (Figure 1C right) that was suggested to be important in the hydroxylation reaction with this substrate (Figure 1B). ${ }^{20}$

In the present study we build on this NRVS-defined geometric structure of the $\mathrm{Fe}^{\mathrm{IV}}=\mathrm{O}$ intermediate in the halogenase. Variable-temperature magnetic circular dichroism (VT MCD) spectroscopy is performed on the $\mathrm{Fe}^{\mathrm{IV}}=\mathrm{O}$ SyrB2 intermediate with bound $\mathrm{Br}^{-}$and correlated with high-level multireference $a b$ initio and density functional theory (DFT) calculations to define the electronic structure of this $\mathrm{Fe}^{\mathrm{IV}}=\mathrm{O}$ intermediate. Quantitative comparison to our previous study ${ }^{16}$ of $\left(\mathrm{TMG}_{3}\right.$ tren $)-\mathrm{Fe}^{\mathrm{IV}}=\mathrm{O}$ elucidates electronic structure contributions to their relative HAA reactivities.

\section{EXPERIMENTAL AND COMPUTATIONAL DETAILS}

\subsection{Sample Preparation}

Samples of the SyrB2 $\mathrm{Br}-\mathrm{Fe}^{\mathrm{IV}}=\mathrm{O}$ intermediate with a concentration of $\sim 1.8 \mathrm{mM}$ were prepared as described in ref 7 and in the Supporting Information of ref 20 (therein see Figure S9).

\subsection{Electronic Absorption (Abs) and Magnetic Circular Dichroism (MCD) Spectroscopy}

The Abs spectrum of the enzyme was measured with the Agilent HP8453 diode array spectrophotometer at $\sim 285 \mathrm{~K}$. UV/vis VT MCD data $\left(16000-30000 \mathrm{~cm}^{-1}\right)$ were collected on a Jasco J810 spectrophotometer with an extended S-20 photomultiplier tube, and nearinfrared (NIR) VT MCD data (5000-16000 $\left.\mathrm{cm}^{-1}\right)$ were collected on a Jasco J730 spectrophotometer with a liquid $\mathrm{N}_{2}$-cooled InSn detector. The sample temperature was measured using a calibrated Cernox resistor (Lakeshore Cryogenics) inserted into the MCD cell. A magnetic field of 7T was applied using an Oxford SM 4000-7T superconducting magnet.

\subsection{Vibronic-Structure Analysis}

The Franck-Condon (FC) vibronic progressions are simulated in the harmonic approximation as a Poisson distribution: 


$$
\Delta \varepsilon=\sum_{n} \Delta \varepsilon_{0} \rightarrow 0 \frac{S^{n}}{n !} \exp \left[-\frac{2.733}{\Delta_{\mathrm{FWHM}}^{2}}\left(E-n \Delta E-E_{0 \rightarrow 0}\right)^{2}\right]
$$

where $S$ is the Huang-Rhys factor defined by the equation $S^{n} / n !=\Delta \varepsilon_{0} \rightarrow_{n} / \Delta \varepsilon_{0} \rightarrow 0$ reflecting the progression band shape, $\Delta E$ is the vibronic spacing corresponding to the frequency of the excited-state $\mathrm{Fe}$-oxo stretching mode (in $\mathrm{cm}^{-1}$ ), $\Delta_{\mathrm{fwhm}}$ is the full width in the halfmaximum of each individual peak in the progression $\left(\right.$ in $\left.\mathrm{cm}^{-1}\right), \Delta \varepsilon$ is the intensity distribution over the band, and $E_{0 \rightarrow 0}$ and $\Delta \varepsilon_{0 \rightarrow 0}$ are the energy (in $\mathrm{cm}^{-1}$ ) and the intensity maximum (in $\mathrm{M}^{-1} \mathrm{~cm}^{-1}$ ) of the first peak in the progression. $E$ is the variable photon energy (in $\mathrm{cm}^{-1}$ ). The excited-state distortion (along Fe-oxo bond) with respect to the ground state, $\Delta Q$ (in $\AA$ ), is obtained from

$$
\Delta Q=8.213 \sqrt{\frac{S}{\mu \Delta E}}
$$

with the reduced mass $\mu$ of the Fe-oxo stretching mode that is considered in this study to be $15 \mathrm{amu} ; S$ and $\Delta E\left(\right.$ in $\left.^{-1}\right)$ are defined above. The parabolic shape of the excited-state potential-energy surface (PES) and its $\Delta Q$ and energy (relative to the ground-state PES) along the mode $\mathrm{Q}$ is derived from the $\mathrm{FC}$ analysis using

$$
E_{\mathrm{PES}}=1.4825 \times 10^{-2} \mu(\Delta E)^{2}\left[Q-\left(Q_{0}+\Delta Q\right)\right]^{2}+E_{\mathrm{min}}
$$

where $\mu$ (in amu), $\Delta Q$ (in $\AA$ ), and $\Delta E$ (in $\mathrm{cm}^{-1}$ ) are defined above; $E_{\mathrm{PES}}$ is the energy of the PES (in $\mathrm{cm}^{-1}$ ) along $Q$ that corresponds to the Fe-oxo bond length (in $\AA$ ) with $Q_{0}$ as the ground-state equilibrium geometry (in $\AA$ ); and $E_{\min }$ is the energy of the excited-state PES minimum (in cm ${ }^{-1}$ ), which is determined as $E_{0 \rightarrow 0}+\left(\Delta E_{\mathrm{GS}}-\Delta E\right) / 2$, where $E_{0 \rightarrow 0}$ and $\Delta E$ are defined above and $\Delta E_{\mathrm{GS}}$ is the frequency of the $\mathrm{Fe}$-oxo stretching mode in the ground state.

\subsection{Structural Model}

If not stated otherwise, the cluster model of the $\mathrm{Br}^{-} / \mathrm{Cl}^{-}$ligating ferryl intermediate, which was taken from ref 20, consists of one Fe center, one halide, one crystal water molecule, truncated (His $116, \mathrm{His}_{235}$, succinate) ligands, truncated second-shell ( $\mathrm{Arg}_{254}, \mathrm{Thr}_{143}, \mathrm{Glu}_{102}$ ) residues, and a substrate fragment with its thioester group capped by a $\mathrm{H}$ atom (see Figure $1 \mathrm{D}$ for the truncated model consisting of 89 atoms). ( $\mathrm{TMG}_{3}$ tren)Fe $\mathrm{IV}^{\mathrm{IV}}=\mathrm{O}$ was taken from ref 16.

For RASSCF/CASSCF/CASPT2 calculations (section 2.6), the size of the structural model of ( $\mathrm{SyrB} 2) \mathrm{Fe}^{\mathrm{IV}}=\mathrm{O}$ was reduced to 53 atoms (only the $\mathrm{Arg}_{254}$ fragment and one (crystal) water molecule are present in the second shell; see Figure S1), while the truncated model of $\left(\mathrm{TMG}_{3}\right.$ tren)Fe $\mathrm{Fe}^{\mathrm{IV}}=\mathrm{O}$ was taken from ref 16. 


\subsection{Density Functional Theory Calculations}

Most of DFT calculations reported in this study were performed using the Turbomole 6.3 program. ${ }^{23}$ Unless otherwise mentioned, the hybrid three-parameter Becke's (B3LYP) ${ }^{24}$ functional with the empirical correction to dispersion effect $(+\mathrm{D} 2)^{25}$ was used throughout. All of the geometry optimizations were carried out using the def2-SVP basis set, whereas the single-point energies were recomputed with the def2-TZVP basis set.

In single-point calculations, to allow for solvation effects, the conductor-like screening model (COSMO) was used with a dielectric constant reflecting the protein environment $\left(\varepsilon_{\mathrm{r}}=\right.$ 4.0).

Reaction and activation Gibbs free energies were evaluated (using the option "frznuclei" for the vibrational analyses of systems with fixed atoms) according to the equation:

$$
\Delta G^{(\neq)}=\Delta E_{\mathrm{el}, \mathrm{solv}}^{(\neq)}+\Delta E_{\mathrm{zPE}}^{(\neq)}-R T \Delta \ln q_{\mathrm{vib}}^{(\neq)} q_{\mathrm{rot}}^{(\neq)} q_{\text {trans }}^{(\neq)}
$$

where $\Delta E_{\mathrm{el}, \text { solv }}^{(\neq)}$is the reaction (or activation) energy of the solvated system (at the B3LYP $+\mathrm{D} 2 /$ def2-TZVP/COSMO $(\varepsilon r=4.0) / / \mathrm{B} 3 \mathrm{LYP}+\mathrm{D} 2 /$ def2-SVP level $), \Delta E_{\mathrm{ZPE}}^{(\neq)}$is the change in zero-point energy, and $-R T \Delta \ln q_{\mathrm{vib}}^{(\neq)} q_{\mathrm{rot}}^{(\neq)} q_{\text {trans }}^{(\neq)}$accounts for the change in the reaction (or activation) entropic terms and the thermal correction to the enthalpy as obtained from a frequency calculation (at $298 \mathrm{~K}, 1 \mathrm{~atm}$; ideal-gas approximation) using the geometry optimization calculations.

\subsection{CASSCF/CASPT2/SO-CASSI Calculations}

The state-average complete active space self-consistent field (SA-CASSCF) ${ }^{26}$ and multistate complete active space second-order perturbation theory (MS-CASPT2) ${ }^{27}$ calculations were carried out using the MOLCAS 7.4 program. ${ }^{28}$ For all of the atoms, the ANO-RCC basis set (contracted to [7s6p5d2f1g] for $\mathrm{Fe}$, [6s5p3d] for $\mathrm{Br}$, [4s3p1d] for the ligating $\mathrm{O}, \mathrm{N}$ atoms, [3s2p] for other N, O, and C atoms, and [2s] for H) was used. The second-order DouglasKroll-Hess (DKH2) one-electron spinless Hamiltonian was applied for all of the calculations in order to allow for spin-free relativistic effects. ${ }^{29}$

The SA-CASSCF/MS-CASPT2 potential energy surfaces along the $\mathrm{Fe}-\mathrm{O}$ vibration mode of the $\mathrm{Br}-\mathrm{Fe}^{\mathrm{IV}}=\mathrm{O}$ intermediate (obtained from the BP86/def2-SVP frequency analysis using the G09 program package $\left.{ }^{30}\right)^{20}$ were calculated with the 16-electrons-in-11-orbitals active space including $5 d_{\mathrm{Fe}}, 3 p_{\mathrm{oxo}}$, and 3 ligand-based orbitals (orbitals and further technical details of the CASSCF calculations are in the Supporting Information (SI), Figure S2). The state-average CASSCF and multistate CASPT2 calculations were performed over the three lowest $S=2$ and ten lowest $S=1$ states.

As an extension of the CASSCF approach, the state-average restricted active space selfconsistent field (SA-RASSCF) ${ }^{31}$ calculations were used for simulating electronic spectra (for technical details, see SI on pp S4-S5 and Figure S3). Within these RASSCF 
calculations, the RAS3 subspace includes Fe $4 d$ orbitals to partially account for the doubleshell effect to improve the accuracy of the calculated spectra. ${ }^{32}$

Spin-orbit couplings (SOCs) were calculated using the spin-orbit complete active space state interaction (SO-CASSI) method and solving the generalized eigenvalue problem of first-order QDPT [taking the atomic mean-field integral (AMFI) spin-orbit Hamiltonian ${ }^{33}$ as the perturbation] to obtain the SOC-corrected quasi-relativistic energies. ${ }^{34}$ To improve the accuracy of the calculations, the CASPT2 energies were used on the diagonal of the twocomponent Hamiltonian matrix.

In all of the CASSCF or RASSCF calculations, a level shift of 0.5 au was used in order to improve convergence. In the CASPT2 calculations, none of the orbitals were frozen, and an imaginary level shift of 0.2 au was used to eliminate intruder states. ${ }^{35}$

\section{RESULTS AND ANALYSIS}

\subsection{Absorption and MCD Spectra of SyrB2 $\mathrm{Br}-\mathrm{Fe} \mathrm{IV}^{\mathrm{IV}}=\mathrm{O}$ Intermediate}

\subsubsection{Band Assignments and Correlation to Spectra of the $\left(\mathrm{TMG}_{3}\right.$ tren)Fe $\mathrm{IV}^{\mathrm{IV}}=0$ Model Complex (from Ref 16)—Figure 2A shows the UV-visible Abs and VT MCD} spectra of the high-spin $(S=2) \mathrm{SyrB} 2 \mathrm{Br}-\mathrm{Fe}^{\mathrm{IV}}=\mathrm{O} / \mathrm{L}-\mathrm{Cpg}$ intermediate. The abs spectrum shows a weak feature at $12000 \mathrm{~cm}^{-1}$ and two more intense broad features centered at 19 000 and $26000 \mathrm{~cm}^{-1}$. These become much more well-resolved and feature-rich in the LT MCD spectrum, which thus allows definitive band assignments for electronic-structure elucidation.

First, within the theory developed in ref 36, fitting the temperature dependence of the MCD bands (data given in Figure 2B varying from $T=2 \mathrm{~K}$ through $60 \mathrm{~K}$ ) allows an estimate of the zero-field splitting (ZFS) parameters that are $\mathrm{D}=+7 \mathrm{~cm}^{-1}$ and $\mathrm{E} / \mathrm{D}=0.02$ for SyrB2 $\mathrm{Br}-$ $\mathrm{Fe}^{\mathrm{IV}}=\mathrm{O}$ (Figure $\mathrm{S} 4$ ). These parameters are in the range of those determined from magnetic Mössbauer spectra of the $\mathrm{Cl}-\mathrm{Fe}^{\mathrm{IV}}=\mathrm{O}$ intermediate in halogenase $\mathrm{CytC} 3\left(\mathrm{D}=+7 \mathrm{~cm}^{-1}\right.$ and $\mathrm{E} / \mathrm{D}=0.02) .{ }^{5}$ Once the ZFS is known, the polarizations of the MCD bands can be determined using the methodology from refs 17, 37 (described in the caption to Figure S4). The positive ZFS D parameter gives the splitting of the $\pm M_{S}$ sublevels of an $S=2$ species with $M_{\mathrm{S}}=0$ lowest in energy. For a $z$-polarized transition, the lowest-energy sublevel at a magnetic field of $7 \mathrm{~T}$ is the MCD-active $M_{\mathrm{S}}=-1$, so the MCD intensity is high at low T and decreases with an increase in $\mathrm{T}$ because the population of the $M_{S}=-1$ sublevel decreases, and the populations of the MCD-inactive $M_{S}=0$ and the opposite-signed $M_{S}=+1$ increase. For $x / y$-polarized transitions, the magnetic field has a nonvanishing component along the $z$ axis for MCD intensity and the lowest sublevel at $7 \mathrm{~T}$ is the MCD-inactive $M_{\mathrm{s}}=0$ sublevel. This leads to MCD intensity that decreases with increasing temperature at a lower rate than the z-polarized MCD intensity due to populations of the MCD-active $M_{\mathrm{S}}=+1$ and $M_{\mathrm{S}}=-1$ sublevels that produce MCD intensities of opposite signs (Figure S4).

In the near-infrared region (NIR), between 6000 and $15000 \mathrm{~cm}^{-1}$, there are distinct positive and negative MCD Franck-Condon (FC) vibronic progressions centered around $11000 \mathrm{~cm}^{-1}$ that form a derivative-shaped pseudo-A term with the negative component at higher energy 
(feature I in the MCD spectrum in Figure 2A). The temperature-dependent behavior of the pseudo-A term feature indicates that it is $x / y$-polarized (Figure $\mathrm{S} 4$ ). This transition has a fairly large MCD-to-absorption intensity $\left(\mathrm{C}_{0} / \mathrm{D}_{0}\right)$ ratio $(0.150)$ allowing it to be assigned as a ligand-field (LF) transition. The NIR VT MCD spectrum of the $\mathrm{SyrB} 2 \mathrm{Br}-\mathrm{Fe}^{\mathrm{IV}}=\mathrm{O}$ intermediate is remarkably similar in terms of band energy, derivative band shape, $\mathrm{C}_{0} / \mathrm{D}_{0}$ ratio, and temperature dependence to the $\mathrm{MCD}$ spectrum of the $S=2\left(\mathrm{TMG}_{3}\right.$ tren) $\mathrm{Fe}^{\mathrm{IV}}=\mathrm{O}$ model complex studied in ref 16 (and included for comparison in Figure 2B and Table 1). It is noteworthy that despite these similarities, the pseudo-A feature in $\mathrm{Br}-\mathrm{Fe}^{\mathrm{IV}}=\mathrm{O}$ is approximately three times weaker than the equivalent $\mathrm{MCD}$ feature in $\left(\mathrm{TMG}_{3}\right.$ tren $) \mathrm{Fe}^{\mathrm{IV}}=\mathrm{O}$ (its $\mathrm{C}_{0} / \mathrm{D}_{0}$ for feature I is $\sim 0.250$ ). Overall, these results allow assignment of the NIR MCD band $\mathrm{I}$ in $(\mathrm{SyrB} 2) \mathrm{Fe}^{\mathrm{IV}}=\mathrm{O}$ as the ${ }^{5} \mathrm{~A} \rightarrow{ }^{5} \mathrm{E}$ LF transition involving electron excitation from the $d_{x z} \pi^{*}$ and $d_{y z} \pi^{*}$ orbitals into the $d_{\mathrm{z} 2} \sigma^{*}$ orbital, transitions that are degenerate in the $C_{3}$ symmetry of $\left(\mathrm{TMG}_{3}\right.$ tren $) \mathrm{Fe}^{\mathrm{IV}}=\mathrm{O}$.

In the $15000-30000 \mathrm{~cm}^{-1}$ region of the MCD spectrum, there are four temperaturedependent MCD features located at 17 500, 21 500, 24000 , and $\sim 27000 \mathrm{~cm}^{-1}$. The two lower-energy bands (labeled II and III in Figure 2A) are determined from the temperature-dependence MCD intensity (Figure $\mathrm{S} 4$ ) to be $z$-polarized $\mathrm{C}$ terms that can be assigned to charge-transfer (CT) transitions on the basis of their low $\mathrm{C}_{0} / \mathrm{D}_{0}$ ratios of 0.005 and 0.050, respectively. The two higher-energy MCD features at $\sim 24000$ and $\sim 27000 \mathrm{~cm}^{-1}$ in Figure 2B cannot be analyzed because of a minor overlapping heme contaminant in the sample (that produces a large MCD contribution). As in the near-infrared region, the UV-vis VT MCD spectra of SyrB2 $\mathrm{Br}-\mathrm{Fe}^{\mathrm{IV}}=\mathrm{O}$ and $\left(\mathrm{TMG}_{3}\right.$ tren) $\mathrm{Fe}^{\mathrm{IV}}=\mathrm{O}$ (bands II and III from Figure 2A and $\mathrm{B}$ ) have very similar spectroscopic characteristics including MCD signs, their polarizations along the molecular $z$ axis, and $\mathrm{C}_{0} / \mathrm{D}_{0}$ ratios. This comparison is summarized in Table 1 and in parallel to ref 16 bands II and III are assigned as oxo-to-Fe CT transitions. However, note that the bands for SyrB2 are shifted $\sim 2000-3000 \mathrm{~cm}^{-1}$ to lower energies as compared to those of the $\left(\mathrm{TMG}_{3}\right.$ tren $) \mathrm{Fe}^{\mathrm{IV}}=\mathrm{O}$ model complex. This shows that the oxo group is a better electron donor in $\mathrm{SyrB} 2 \mathrm{Br}-\mathrm{Fe}^{\mathrm{IV}}=\mathrm{O}$ than in $\left(\mathrm{TMG}_{3}\right.$ tren $) \mathrm{Fe}^{\mathrm{IV}}=\mathrm{O}$ indicating that the ligand field strength of the metalloenzyme active site is weaker than that of the model complex. Note, from this correlation to the $\mathrm{Fe}^{\mathrm{IV}}=\mathrm{O}$ model complex that has no $\mathrm{Br}^{-}$ligand, the $\mathrm{Br}$-to- $\mathrm{Fe}^{\mathrm{IV}} \mathrm{CT}$ transitions must be higher in energy than band III in the enzyme. This is also consistent with calculations (vide infra).

3.1.2. Band I Pseudo-A Term and Vibronic Structure Analysis-The pseudo-A term of band I has a well-resolved vibronic structure with irregular spacing in both the positive and negative components indicating overlapping progressions of opposite sign. Indeed, the pseudo-A term is reasonably fitted by two Franck-Condon (FC) vibronic progressions (see Figure 3A). These FC progressions differ mostly in band shape, as represented by the Huang-Rhys parameters ( $S=0.6$ vs 2.6 for the lower-energy positive vs higher-energy negative component) and in the spacing between adjacent peaks that gives the frequency of the $\mathrm{Fe}-$ oxo stretching mode in the excited state ( $\Delta E=860 \mathrm{vs} 650 \mathrm{~cm}^{-1}$ for the positive vs negative component; $c f ., 710$ vs $880 \mathrm{~cm}^{-1}$ for the model complex $\left(\mathrm{TMG}_{3}\right.$ tren $) \mathrm{Fe}^{\mathrm{IV}}=\mathrm{O}$ from ref 16$)$. Using these $\mathrm{FC}$ parameters and the methodology in section 2.3, the two harmonic exited-state potential-energy surfaces (PES) corresponding to 
the positive (i.e., left circularly polarized, LCP) and the negative (i.e., right circularly polarized, $\mathrm{RCP}$ ) vibronic progressions were derived (Figure 3B). These parabolas are clearly different: the PES of the RCP state is broad and more distorted from the ground-state minimum and higher in energy at the ground-state equilibrium geometry than the PES for the LCP state. From these PESs, the RCP state becomes lower in energy at the longer Fe-O bond lengths relevant to the TS of the $\pi$ channel for HAA (vide infra)

There are thus quantitative differences in what was found from the MCD spectrum of the $\left(\mathrm{TMG}_{3}\right.$ tren $) \mathrm{Fe}^{\mathrm{IV}}=\mathrm{O}$ species for the ${ }^{5} \mathrm{~A} \rightarrow{ }^{5} \mathrm{E}$ LF transitions relative to the results for $(\mathrm{SyrB} 2) \mathrm{Fe}^{\mathrm{IV}}=\mathrm{O}$. For $\left(\mathrm{TMG}_{3}\right.$ tren $) \mathrm{Fe}^{\mathrm{IV}}=\mathrm{O}$, the high-energy RCP component of the pseudoA term in the NIR MCD spectrum had a smaller Huang-Rhys factor and larger vibronic spacing $\left(S=1.2 \text { and } \Delta E=880 \mathrm{~cm}^{-1}\right)^{16}$ reflecting a narrower, less distorted PES for the RCP state as compared to the PES of the LCP state $\left(S=2.8\right.$ and $\left.\Delta E=710 \mathrm{~cm}^{-1}\right)$. This requires a significant difference in the nature of the interactions among the excited states that shape these ${ }^{5}$ E PESs. In the trigonal bipyramidal (TBP) $C_{3}$ model complex $\left(\mathrm{TMG}_{3}\right.$ tren $) \mathrm{Fe}^{\mathrm{IV}}=\mathrm{O}$, the high-energy, narrower, and less distorted RCP-active PES resulted from a strong spinorbit coupling (SOC) interaction between this component of the in-state SOC split ${ }^{5} \mathrm{E}\left(d_{x z / y z}\right.$ $\pi^{*} \rightarrow d_{z^{2}} \sigma^{*} \mathrm{LF}$ ) state and a nearby triplet. ${ }^{16}$ For $\mathrm{SyrB} 2 \mathrm{Br}-\mathrm{Fe}^{\mathrm{IV}}=\mathrm{O}$, it is the low-energy LCP PES that is narrower and less distorted. As explained below this results from a lowsymmetry splitting of the $d_{x z / y z} \pi^{*} \rightarrow d_{Z^{2}} \sigma^{*} \mathrm{LF}^{5} \mathrm{E}$ state, due to the presence of the equatorial halide ligand (Figure 4).

We finally note that the temperature-dependent MCD data for $(\mathrm{SyrB} 2) \mathrm{Fe}^{\mathrm{IV}}=\mathrm{O}$ in the band $\mathrm{I}$ region require more than two FC progressions. From the FC analysis presented in Figure 3A, the first, fourth, and the fifth negative peaks do not overlap with the LCP peaks and hence the intensities of these peaks should behave the same with a change of temperature.

However, from Figure 5A, the temperature dependence of the first negative peak is different from that of the fourth and fifth negative peaks. This indicates that these peaks, in fact, belong to different RCP vibronic progressions. This is reflected in Figure 5B by a three FC progression fit of the pseudo-A term feature where the first (lower-energy) RCP progression has a distinctly larger $S$ and smaller $\Delta E$ than its high-energy RCP cognate. The origin of the two RCP progressions is evaluated in section 3.2.2.

\subsection{Quantum-Chemical (Multiconfigurational and Multireference) Calculations; Spectroscopy}

\subsubsection{Calculated Electronic Spectrum and Correlation to MCD Data-The}

structural model for the multiconfigurational/multireference calculations was obtained, as described in section 2.4, by truncation of the five-coordinate trigonal-bipyramidal (TBP) $\mathrm{Fe}^{\mathrm{IV}}=\mathrm{O}$ structure, which was determined in ref 20 from synchrotron-based nuclear resonance vibrational spectroscopy (NRVS) in combination with DFT calculations (for structures see Figure S1). The RASSCF calculated electronic spectrum of this SyrB2 $\mathrm{Br}$ $\mathrm{Fe}^{\mathrm{IV}}=\mathrm{O}$ structure along with that of $\left(\mathrm{TMG}_{3}\right.$ tren $) \mathrm{Fe}^{\mathrm{IV}}=\mathrm{O}$ is shown in Figure 6. Importantly, these calculations correlate well with the experimental spectra in Figure 2:

We first consider the LF region, band I. For SyrB2 $\mathrm{Br}-\mathrm{Fe}^{\mathrm{IV}}=\mathrm{O}$, there are two calculated near-infrared $x / y$-polarized transitions with LF character, the $d_{x z / y z} \pi^{*} \rightarrow d_{z}^{2} \sigma^{*}$ transitions 
that are split by $1520 \mathrm{~cm}^{-1}$ (as shown in Figure 6; cf. experimental $700 \mathrm{~cm}^{-1}$ ) and have energies that are close to values obtained from the experimental MCD pseudo-A term, band I in Figure 2A (i.e., calculated 10280 and $11800 \mathrm{~cm}^{-1}$ vs experimental 9500 and 10200 $\mathrm{cm}^{-1}$ ). These calculated transition energies are comparable to that of the corresponding 2fold degenerate transition in the $C_{3}$ symmetric $\left(\mathrm{TMG}_{3}\right.$ tren) $\mathrm{Fe}^{\mathrm{IV}}=\mathrm{O}$ model complex, which also agrees with the experimental data in Figure 2B.

We next consider the $\mathrm{CT}$ spectrum of $\left(\mathrm{TMG}_{3}\right.$ tren $) \mathrm{Fe}^{\mathrm{IV}}=\mathrm{O}$. From group theory for effective $C_{3}$ symmetry, three oxo $\pi \rightarrow d_{X z, y z} \pi^{*} \mathrm{CT}$ transitions are predicted: one is 2-fold degenerate $\left({ }^{5} \mathrm{E}\right)$ and $\mathrm{x} / \mathrm{y}$-polarized, while two are nondegenerate $\left({ }^{5} \mathrm{~A}\right)$ and z-polarized. The

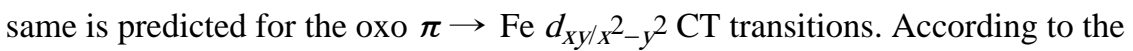
nonrelativistic multiconfigurational calculations for $\left(\mathrm{TMG}_{3}\right.$ tren $) \mathrm{Fe}^{\mathrm{IV}}=\mathrm{O}$, the lowest-energy CT state is the oxo $\pi \rightarrow d \pi^{*}{ }^{5} \mathrm{E}$ state at $\sim 24630 \mathrm{~cm}^{-1}$, whereas the two other oxo $\pi \rightarrow$ $d \pi^{*}$ states (the ${ }^{5} \mathrm{~A}$ 's) are at $\sim 25040$ and $\sim 31290 \mathrm{~cm}^{-1}$ (Figure 6). The three oxo $\pi \rightarrow \mathrm{Fe}$

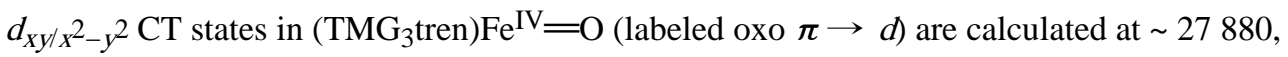
$\sim 29$ 930, and $\sim 31290 \mathrm{~cm}^{-1}$, respectively (Figure 6); the first is z-polarized and has the largest oscillator strength among all of excitations in the $0-32000 \mathrm{~cm}^{-1}$ region. This lowest oxo $\pi \rightarrow d \mathrm{CT}$ is attributed to the intense band III in the experimental spectrum of the model complex in Figure 2B. While the lowest-energy experimental CT transition, i.e., band II in the MCD spectrum of the model compound Figure 2B, is z-polarized (Table 1), the lowest calculated oxo-to-Fe CT transition $\left({ }^{5} \mathrm{~A}_{\mathrm{gs}} \rightarrow{ }^{5} \mathrm{E} \mathrm{CT}\right)$ in the model in Figure 6 is $\mathrm{x} / \mathrm{y}$ polarized. This discrepancy can be reconciled by the fact that the lowest-energy calculated zpolarized nondegenerate oxo $\pi \rightarrow d \pi^{*} \mathrm{CT}$ transition $\left({ }^{5} \mathrm{~A}_{\mathrm{gs}} \rightarrow{ }^{5} \mathrm{ACT}\right)$ is predicted only $500 \mathrm{~cm}^{-1}$ above the ${ }^{5} \mathrm{~A}_{\mathrm{gs}} \rightarrow{ }^{5} \mathrm{E} \mathrm{CT}$. This z-polarized oxo $\pi \rightarrow d \pi^{*} \mathrm{CT}\left(\sim 25040 \mathrm{~cm}^{-1}\right)$ has ${ }^{5} \mathrm{~A}$ symmetry and can undergo configuration interaction with the most intense $\mathrm{z}$ polarized oxo $\pi \rightarrow$ Fe $d \mathrm{CT}$ (band III). Even a few percent CI mixing would produce significant z-polarized intensity and give rise to band II in Abs and MCD spectra of the ferryl model compound (Figure 2B).

Taking advantage of the analysis of the oxo-to-Fe CTs in $\left(\mathrm{TMG}_{3}\right.$ tren $) \mathrm{Fe}^{\mathrm{IV}}=\mathrm{O}$, the eight calculated lowest-energy low-symmetry split CT transitions for the $\mathrm{SyrB} 2 \mathrm{Br}-\mathrm{Fe}^{\mathrm{IV}}=\mathrm{O}$ active site can be straightforwardly identified. The calculated transitions at $\sim 21040$ and $23140 \mathrm{~cm}^{-1}$ are the low-symmetry split components of the lowest-energy 2-fold degenerate $\mathrm{x} / \mathrm{y}$ - polarized oxo $\pi \rightarrow d \pi^{*} \mathrm{CT}$ (Figure 6 , red). However, these two excitations are masked by the more intense z-polarized transitions, oxo $\pi \rightarrow d \pi^{*} \mathrm{CT}$ calculated at $\sim 21760 \mathrm{~cm}^{-1}$ and oxo $\pi \rightarrow d$ at $\sim 23220 \mathrm{~cm}^{-1}$ (bold red lines in Figure 6), that correlate with the first and the second ${ }^{5} \mathrm{~A}_{\mathrm{gs}} \rightarrow{ }^{5} \mathrm{~A} \mathrm{CT}$ in the $\mathrm{C}_{3}$-symmetric $\left(\mathrm{TMG}_{3}\right.$ tren $) \mathrm{Fe}^{\mathrm{IV}}=\mathrm{O}$ complex, respectively. Thus, bands II and III in the experimental spectrum of $(\mathrm{SyrB} 2) \mathrm{Fe}^{\mathrm{IV}}=\mathrm{O}$ in Figure 2A can be assigned as the oxo $\pi \rightarrow d \pi^{*}$ and oxo $\pi \rightarrow d \mathrm{CT}$ transitions, respectively. Importantly, these two z-polarized CT transitions (the lower of which is less intense) are shifted to lower energies and less split as compared to their CT cognates calculated for the model complex. These computational results are in the good agreement with the experimental data (cf. Figures 6 and 2).

3.2.2. Pseudo-A Term (Band I)-Here we address the ${ }^{5} \mathrm{~A} \rightarrow{ }^{5} \mathrm{E}$ LF transition in SyrB2 $\mathrm{Br}-\mathrm{Fe}^{\mathrm{IV}}=\mathrm{O}$ at $\sim 11000 \mathrm{~cm}^{-1}$ in Figure 6, which is split by the distortion from $C_{3}$ symmetry 
due to the equatorial bromide. In comparing this region between $\mathrm{SyrB} 2 \mathrm{Br}-\mathrm{Fe}^{\mathrm{IV}}=\mathrm{O}$ and $\left(\mathrm{TMG}_{3}\right.$ tren $) \mathrm{Fe}^{\mathrm{IV}}=\mathrm{O}$, there are several differences. The $C_{3}$ degenerate pair of $d_{x z / y z} \pi^{*} \rightarrow$ $d_{z^{2}} \sigma^{*}$ LF excited states split in energy in the low-symmetry structure of $\mathrm{Br}-\mathrm{Fe}^{\mathrm{IV}}=\mathrm{O}$ giving rise to the lower-energy LCP and higher-energy RCP transitions. These gain MCD intensities through a $\mathrm{C}$-term mechanism ${ }^{36}$ that involves SOC between these states to form a derivative-shaped pseudo-A term. The equations that govern $\mathrm{C}$-term intensities related to these SOC-interacting excited states (labeled 2 and 3 below; 1 is the ground state ${ }^{5} \mathrm{~A}$ ) is

$$
\begin{aligned}
& C_{0}^{1 \rightarrow 2}=-\frac{g_{z}}{6\left(E_{3}-E_{2}\right)}\left(D_{x}^{1 \rightarrow 3} D_{y}^{1 \rightarrow 2}-D_{y}^{1 \rightarrow 3} D_{x}^{1 \rightarrow 2}\right) L_{z}^{3,2} \\
& C_{0}^{1 \rightarrow 3}=-\frac{g_{z}}{6\left(E_{2}-E_{3}\right)}\left(D_{x}^{1 \rightarrow 2} D_{y}^{1 \rightarrow 3}-D_{y}^{1 \rightarrow 2} D_{x}^{1 \rightarrow 3}\right) L_{z}^{2,3}
\end{aligned}
$$

where $E_{2}$ and $E_{3}$ are energies of states 2 and $3, g_{Z}$ is the z-component of the Zeeman tensor for the ground state (state 1 ), $D_{x}^{1 \rightarrow 2}$ is the $x$-component of the transition dipole moment from 1 to 2 , and $L_{z}^{2,3}$ is the z-term of the SOC operator between states 2 and 3, etc. Using CASPT2 calculations, state 2 is determined to arise from the $d_{y z} \pi^{*} \rightarrow d_{z^{2}} \sigma^{*}$ LF transition ( $\mathrm{Fe}-\mathrm{oxo}$ and $\mathrm{Fe}-\mathrm{Br}$ define the $\mathrm{z}$ and $\mathrm{y}$ axes, respectively) that is calculated to be lower in energy than the $d_{x z} \pi^{*} \rightarrow d_{z^{2}} \sigma^{*}$ LF state (state 3). This energy difference is due to the $d_{y z}$ $\pi^{*}$ orbital that interacts with the halide and is at higher energy than $d_{X Z} \pi^{*}$ and thus lowering the energy of the $d_{y z} \pi^{*} \rightarrow d_{z^{2}} \sigma^{*}$ state relative to the $d_{x z} \pi^{*} \rightarrow d_{z^{2}} \sigma^{*}$ transition. As given in Figure 7, calculations, in agreement with the experiment, identify the LCPactive $d_{y z} \pi^{*} \rightarrow d_{z^{2}} \sigma^{*}$ state to be lower in energy (state 2) than its RCP-active $d_{x z} \pi^{*} \rightarrow$ $d_{Z^{2}} \sigma^{*}$ cognate (state 3). It is noteworthy that calculated SOC interaction between LCP and RCP states is $\sim 120 \mathrm{~cm}^{-1}$ in $\mathrm{SyrB} 2 \mathrm{Br}-\mathrm{Fe}^{\mathrm{IV}}=\mathrm{O}$, which is smaller than $\mathrm{SOC}$ between the corresponding states in $\left(\mathrm{TMG}_{3}\right.$ tren $) \mathrm{Fe}^{\mathrm{IV}}=\mathrm{O}\left(\sim 220 \mathrm{~cm}^{-1}\right) ;{ }^{16}$ this is in line with the observation of lower pseudo-A term MCD intensity (and lower $\mathrm{C}_{0} / \mathrm{D}_{0}$ ratio) for the $\mathrm{Br}$ $\mathrm{Fe}^{\mathrm{IV}}=\mathrm{O}$ species than for $\left(\mathrm{TMG}_{3}\right.$ tren $) \mathrm{Fe}^{\mathrm{IV}}=\mathrm{O}$ (cf., Figure 2 and Table 1$)$. This decreased SOC indicates a larger relativistic nephelauxetic effect due to the higher covalency of the $\mathrm{Fe}-$ oxo bond relative to the N-based chelating ligation in $\left(\mathrm{TMG}_{3} \operatorname{tren}\right) \mathrm{Fe}^{\mathrm{IV}}=\mathrm{O}$ (vide infra).

To further correlate calculations with the experimental data, the CASPT2 ground-state and two lowest excited-state PESs in the Fe-oxo coordinate were evaluated (Figure 8).

Importantly, the excited-state PESs reproduce the main features of the MCD-derived PESs (from Figure 3B): (i) the LCP-active PES is lower in energy at ground-state equilibrium than RCP-active PES (quantitatively the calculations overestimate the experiment by a factor of 2 that corresponds to an error of $\sim 1.5 \mathrm{kcal} \mathrm{mol}^{-1}$ ); (ii) the LCP-state distortion is smaller than that of the RCP state, $\Delta Q_{\mathrm{LCP}}=0.095 \AA$ vs $\Delta Q_{\mathrm{RCP}}=0.124 \AA$ (cf., experimental values in Figure 3B); (iii) the RCP PES decreases in energy more than the LCP PES in going from the ground-state equilibrium (indicated by a vertical line in Figure 8 ) to their respective excited-state PES minima; (iv) the frequency of the LCP state $\mathrm{Fe}-$ oxo stretching mode 
(estimated from a third-order Taylor expansion fit of the PES) is higher than that of the RCP state, $\Delta E_{\mathrm{LCP}} \approx 870 \mathrm{~cm}^{-1}$ vs $\Delta E_{\mathrm{RCP}} \approx 790 \mathrm{~cm}^{-1}$ (cf., experimental values in Figure 3B).

The different PES curvatures and distortions of the LCP and RCP states in the vicinity of the ground-state equilibrium are attributed to the anisotropy of the $\pi$ FMOs. Namely, the $p$ orbitals of the $\mathrm{Br}^{-}$ligand interact with $d_{y z} \pi^{*}$ (y along $\mathrm{Fe}-\mathrm{Br}$, vide supra; orbitals shown in Figure 8) but not with $d_{x z} \pi^{*}$. As a consequence, the $d_{y z} \pi^{*}$ has less Fe $d$ character than $d_{x z}$ $\pi^{*}$. Thus, $d_{y z} \pi^{*}$ is less antibonding with respect to Fe-oxo. The LCP $d_{y z} \pi^{*} \rightarrow d_{z^{2}} \sigma^{*}$ PES thus has a smaller Hellmann-Feynman distortive force along the $\mathrm{Fe}$-oxo stretching mode than the RCP $d_{X Z} \pi^{*} \rightarrow \sigma^{*}$ PES. The higher Fe-oxo stretching frequency of the LCP state as compared to RCP is then mostly influenced by the difference in PES curvature at longer $\mathrm{Fe}-$ O distances ( $>1.75 \AA$ ) that is caused by the difference in halide admixture into the oxo $d \pi_{y z}$ vs $d \pi_{x z}$ orbitals. This makes $\mathrm{Fe}^{\mathrm{IV}}=\mathrm{O} \rightarrow \mathrm{Fe}^{\mathrm{III}}-\mathrm{O}^{\bullet-}$ polarization in the $\pi_{y z}$ orbital at longer $\mathrm{Fe}-\mathrm{O}$ distances more difficult due to the higher halide donation (see also Figure S5). These findings are reflected in the MCD data by the two (positive and negative) vibronic progressions, with the positive structure associated with the $d_{y z} \pi^{*} \rightarrow d_{z^{2}} \sigma^{*}$ transition having a higher $\mathrm{Fe}-$ oxo stretching frequency and smaller Huang-Rhys factor.

From the more detailed analyses of the temperature dependence of the vibronic progressions in Figure 5, there are in fact two negative progressions for $\mathrm{SyrB} 2 \mathrm{Br}-\mathrm{Fe}^{\mathrm{IV}}=\mathrm{O}$. The CASPT2/SO-CASSI calculations (Figure S6) indicate that SyrB2 has a strong SOC interaction between the RCP component of the low-symmetry perturbed $\mathrm{LF}^{5} \mathrm{E}$ state and a close-lying triplet state (SOC matrix element of $480 \mathrm{~cm}^{-1}$; such an interstate SOC was also observed for $\left(\mathrm{TMG}_{3}\right.$ tren) $\mathrm{Fe}^{\mathrm{IV}}=\mathrm{O}$ (see ref 16)). This interstate $\mathrm{SOC}$ would give rise to two RCP FC progressions, in line with the experimentally observed unequal temperature behavior of the negative vibrational peaks (Figure 5).

\subsection{Quantum-Chemical Calculations; Reactivity}

According to the NRVS spectroscopy in ref 20, the bromide and chloride ligating $(\mathrm{SyrB} 2) \mathrm{Fe}^{\mathrm{IV}}=\mathrm{O}$ structures are structurally equivalent. $A b$ inito calculations performed in this work (Figure S7) predict that there is no essential difference in their absorption spectra, indicating that electronic structures of the $\mathrm{Br}-\mathrm{Fe}^{\mathrm{IV}}=\mathrm{O}$ and $\mathrm{Cl}-\mathrm{Fe}^{\mathrm{IV}}=\mathrm{O}$ intermediates are equivalent in the region $0-30000 \mathrm{~cm}^{-1}$. In this section, we therefore correlate our results from spectroscopically based electronic-structure analyses for $\mathrm{SyrB} 2 \mathrm{Br}-\mathrm{Fe}^{\mathrm{IV}}=\mathrm{O}$ with reactivity calculations on the chloride-bound active site for comparison to kinetic results (ref 7.).

From ref 20, a reaction coordinate was generated for $\mathrm{H}$ atom abstraction from the native substrate $\mathrm{L}-\mathrm{Thr}$ by the chloride-ligating $\mathrm{Fe}^{\mathrm{IV}}=\mathrm{O}$ intermediate of SyrB2. It was found that this reaction involves the $d_{X Z} \pi^{*}$ FMO that, due to the perpendicular orientation of the substrate $\mathrm{C}-\mathrm{H}$ bond relative to the $\mathrm{Fe}-\mathrm{oxo}$ bond axis (and $\mathrm{Fe}-\mathrm{Cl}$ axis $(\mathrm{y})$ ), interacts with the $\sigma(\mathrm{C}-\mathrm{H})$ bonding orbital. This leads to the formation of a ferric intermediate, halide-Fe $\mathrm{F}^{\mathrm{II}}$ $\mathrm{OH}$ with five $a$-electrons on the trigonal bipyramidal $\mathrm{Fe}^{\mathrm{III}}$ center and the carbon radical. This parallels the $\pi$-mechanism of the HAA reaction in the trigonal bipyramidal model complex $\left(\mathrm{TMG}_{3}\right.$ tren $) \mathrm{Fe}^{\mathrm{IV}}=\mathrm{O}$ that undergoes a self-decay process. ${ }^{15 \mathrm{a}, 16}$ Both of these calculated HAA reactions are shown in Figure 9. The parallel reactivities of both the 
synthetic and enzymatic active sites, along with their parallel spectroscopic data, provide a basis for evaluating electronic structure contributions to the protein $\pi$-promoted HAA reactivity.

3.3.1. Configuration Evolution of FMOs-From section 3.2.1, the calculations correlated with spectroscopy show the oxo-to-Fe CT states to be lower in energy in SyrB2 $\mathrm{Br}-\mathrm{Fe}^{\mathrm{IV}}=\mathrm{O}$ than those in $\left(\mathrm{TMG}_{3}\right.$ tren $) \mathrm{Fe}^{\mathrm{IV}}=\mathrm{O}$. This reflects larger $\mathrm{CI}$ mixing of the oxoto-Fe $\left(p_{y} \pi \rightarrow d_{y z} \pi^{*}\right.$ and $\left.p_{x} \pi \rightarrow d_{x z} \pi^{*}\right)$ CT configurations into the $d_{y z} \pi^{*} \rightarrow d_{z^{2}} \sigma^{*}$ and $d_{X Z} \pi^{*} \rightarrow d_{Z^{2}} \sigma^{*}$ LF states at the ground-state equilibrium geometry of (SyrB2)$\mathrm{Fe}^{\mathrm{IV}}=\mathrm{O}$ as compared to $\left(\mathrm{TMG}_{3}\right.$ tren $) \mathrm{Fe}^{\mathrm{IV}}=\mathrm{O}($ cf., $\sim 40 \%$ vs $~ 20 \%$ CT admixtures into the $d_{X Z} \pi^{*} \rightarrow d_{Z^{2}} \sigma^{*}$ LF state; Figure 10). This is consistent with the more covalent $\mathrm{Fe}-\mathrm{O}$ bond in SyrB2 than that in $\mathrm{TMG}_{3}$ tren. From Figure 10, in passing from the ground-state equilibrium to the transition-state $\mathrm{Fe}-\mathrm{O}$ bond lengths, the dashed line representing the oxyl $\mathrm{Fe}^{\mathrm{III}}$ character evolves more rapidly for the enzyme than for the model complex (cf. $\sim 65 \%$ vs $\sim 35 \%$ of Fe $\mathrm{Fe}^{\mathrm{III}}-\mathrm{O}^{\circ-}$ admixtures into the $d_{X Z} \pi^{*} \rightarrow d_{Z^{2}} \sigma^{*}$ LF state at the TS Fe-O lengths in Figure 10). While both $\pi^{*}$ FMOs in $\mathrm{TMG}_{3}$ tren remain equivalent along the $\mathrm{Fe}-\mathrm{O}$ reaction coordinate (i.e., oxyl character in both $\pi$ directions evolves equally), the $\pi$ anisotropy in $\mathrm{SyrB} 2$ leads at longer $\mathrm{Fe}-\mathrm{O}$ distances to the increased oxyl character oriented in the direction of the substrate (cf. $60 \%$ of $\pi_{y z}$-oxyl vs $65 \%$ of $\pi_{x z}$-oxyl at the TS; Figure S5). This correlates with the difference in halide donation to $d_{y z} \pi^{*}$ relative to the $d_{x z} \pi^{*}$ orbital; the latter thus undergoes more $\mathrm{Fe}^{\mathrm{IV}}=\mathrm{O} \rightarrow \mathrm{Fe}^{\mathrm{III}}$-oxyl polarization at the $\mathrm{TS}$ (section 3.2.2).

In correlating from the spectroscopic analysis to reactivity, only the LF RCP-active state, corresponding to the $d_{X Z} \pi^{*} \mathrm{FMO}$, is involved in the HAA $\pi$ pathway, as this is oriented toward the substrate cavity. While this state is higher in energy than the LCP $d_{y z} \pi^{*}$ state in ground-state equilibrium geometry, it has a softer PES in the Fe-O bond (Figure 8) and becomes lower in energy at $\mathrm{Fe}-\mathrm{O}$ lengths (i.e., $>1.82 \AA$ ) corresponding to the transition state for $\mathrm{C}-\mathrm{H}$ abstraction.

Finally, in analogy to the MCD study in ref 16, it is noteworthy that for SyrB2 halide$\mathrm{Fe}^{\mathrm{IV}}=\mathrm{O}$ there are two additional $S=2$ (ground and the lowest-energy oxo-to-Fe CT) states capable of an $\mathrm{H}$ atom abstraction. However, in contrast to $\mathrm{TMG}_{3}$ tren, these two states associated with one $\sigma$ and one $\pi\left(S_{\mathrm{Fe}}^{\mathrm{III}}=3 / 2\right)$ HAA channels are not operative in SyrB2. First, the $\sigma$-channel that is associated with $d \sigma^{*}$ FMO is excluded due to the perpendicular orientation of the substrate with respect to the $\mathrm{Fe}-\mathrm{O}$ vector (Figure 9A). Second, in comparison to $\mathrm{TMG}_{3}$ tren, the PES of the lowest-energy oxo-to-Fe CT state in SyrB2 (Figure $\mathrm{S} 8$ ) is less distorted and steeper at longer $\mathrm{Fe}-\mathrm{O}$ distances so that it becomes higher in energy for Fe-O lengths of $>1.9 \AA$. This indicates that the $\pi\left(S_{\mathrm{Fe}}{ }^{\mathrm{III}}=3 / 2\right)$-channel for HAA is less accessible in SyrB2 than that in $\left(\mathrm{TMG}_{3}\right.$ tren $) \mathrm{Fe}^{\mathrm{IV}}=\mathrm{O}$. This difference in PES curvature is attributed to a difference in H-bonding to the oxo moiety by its environment (two H-bonds in $\mathrm{SyrB} 2$ vs no H-bond in $\mathrm{TMG}_{3}$ tren, Figure S8).

3.3.2. H Atom Abstraction by $\mathrm{Fe}^{\mathrm{IV}}=0$; Correlation of SyrB2 to $\mathrm{TMG}_{3}$ tren-For the comparison of HAA in SyrB2 vs $\mathrm{TMG}_{3}$ tren, the experimental $k_{\text {cat }}$ values $(0.071$ vs 0.02 $\left.\mathrm{s}^{-1}\right)^{7,15 \mathrm{a}}$ indicate that activation free energies in both systems are of similar magnitudes, 19.1 
vs $19.9 \mathrm{kcal} \mathrm{mol}^{-1}$, slightly favoring the enzyme. However, there is a large difference in the strengths of the substrate $\mathrm{C}-\mathrm{H}$ bonds. Experimentally, for methyl groups of small molecules representing threonine (2-propanol) and the chelate ligand (trimethylamine), these are $94^{7}$ and $86 \pm 2^{38} \mathrm{kcal} \mathrm{mol}^{-1}$, respectively. The calculated difference using the present methodology is $10 \mathrm{kcal} \mathrm{mol}^{-1}$. The fact that $(\mathrm{SyrB} 2) \mathrm{Fe}^{\mathrm{IV}}=\mathrm{O}$ is capable of an $\mathrm{H}$ atom abstraction from a stronger $\mathrm{C}-\mathrm{H}$ bond with a lower reaction barrier suggests that the enzyme is more reactive in HAA than its synthetic counterpart.

DFT calculations are consistent with the experimental results (Table 2): the barrier of the $\pi\left(S_{\mathrm{Fe}}^{\mathrm{III}}=5 / 2\right)$-controlled HAA reaction in SyrB2, calculated for the cluster model in the absence of the second-shell Arg residue (see footnote in Table 2), is lower than the corresponding pathway in the model complex ( $c f ., \Delta G^{\ddagger} 19.8 \mathrm{vs} 21.4 \mathrm{kcal} \mathrm{mol}^{-1}$; TSs shown in Figure S9; for $\pi$-trajectories in SyrB2 vs $\mathrm{TMG}_{3}$ tren, see Figure 9) despite its larger endergonicity ( $c f ., \Delta G^{\circ} 2.3 \mathrm{vs} 0.5 \mathrm{kcal} \mathrm{mol}^{-1}$ ). The fact that the thermodynamically less favorable reaction is kinetically more feasible indicates an increased intrinsic reactivity of the enzyme system. Indeed, elimination of the effect of the thermodynamic driving force on the reaction barrier through Marcus theory gives an intrinsic barrier $\Delta G_{\text {intr }}\left(=\left[\Delta G^{\neq}-1 / 2 \Delta G\right.\right.$ $\left.\left.{ }^{\circ}+\left(\Delta G^{\nexists 2}-\Delta G^{\ddagger} \Delta G^{\circ}\right)^{1 / 2}\right] / 2\right)^{39}$ of 18.6 (SyrB2) and $21.6 \mathrm{kcal} \mathrm{mol}^{-1}$ (TMG 3 tren). The lowered intrinsic barrier for $\pi$-controlled HAA in the enzyme correlates well with the increased $\pi$-oxyl character of enzymatic $\mathrm{Fe}^{\mathrm{IV}}=\mathrm{O}$ relative to the model ferryl complex at the TS that was revealed by the spectrocopically supported calculations of the lowest excited state in section 3.3.1.

\section{DISCUSSION}

This study on SyrB2 has focused on using MCD spectroscopy to determine the electronic structure of the $\mathrm{Fe}^{\mathrm{IV}}=\mathrm{O}$ intermediate based on its geometric structure from NRVS in ref 20 and quantitative comparisons to studies on $\mathrm{TMG}_{3}$ tren. ${ }^{16}$ Importantly, there are strong parallels to the $\mathrm{MCD}$ spectra of the $\left(\mathrm{TMG}_{3}\right.$ tren $) \mathrm{Fe}^{\mathrm{IV}}=\mathrm{O}$ model complex (i.e., energies and signs of MCD bands, and related spectroscopic characteristics including $\mathrm{C}_{0} / \mathrm{D}_{0}$ ratios, ground-state ZFS and polarizations of the electronic transitions) that confirm the $\sim C_{3}$ TBP arrangement of the $\mathrm{Fe}^{\mathrm{IV}}=\mathrm{O}$ site in $\mathrm{SyrB} 2$ and allow us to define its ground and low-lying excited electronic states that relate to its FMOs. However, the comparison also reveals differences: the oxo $\pi \rightarrow d \pi^{*}$ CT transitions are shifted down in energy in SyrB2, the $\mathrm{C}_{0} / \mathrm{D}_{0}$ ratio for band $\mathrm{I}$ is reduced by a factor of $\sim 2$, and the vibronic structure in the $\sim 12000 \mathrm{~cm}^{-1}$ (pseudo-A) band I, assigned as the pair of $d \pi^{*} \rightarrow d \sigma^{*}$ LF transitions, is different. These observations reflect quantitative differences in the FMOs. The lower-energy CT reflects a smaller energy gap between oxo $p_{x / y}$ and $d_{x z / y z} \pi^{*}$ orbitals indicating a greater oxo donor interaction reflecting a weaker donor ligand set for the SyrB2 active site. This is also consistent with the lower $\mathrm{C}_{0} / \mathrm{D}_{0}$ ratio of feature $\mathrm{I}$ in $\mathrm{Br}-\mathrm{Fe}^{\mathrm{IV}}=\mathrm{O}$ relative to $\left(\mathrm{TMG}_{3}\right.$ tren $) \mathrm{Fe}^{\mathrm{IV}}=\mathrm{O}$ as this increased oxo character lowers the SOC. The change in vibronic structure indicates a $\pi$ anisotropy in SyrB2 due to the equatorial halide ligand (Scheme 1A and B), i.e., a low-symmetry splitting of the $d_{X Z} \pi^{*}$ and $d_{y z} \pi^{*}$ orbitals with $d_{X Z} \pi^{*}$ being nonbonding with the $\mathrm{Br}^{-}$(Scheme 1C). This $\pi$ anisotropy results in different shapes of the PESs along the Fe-oxo stretching coordinate. This leads to a lowest-energy $d_{X Z} \pi^{*}$ FMO orbital at longer $\mathrm{Fe}-\mathrm{O}$ distances that is oriented toward the substrate cavity (Scheme $1 \mathrm{C}$ ). 
$\mathrm{Ab}$ initio calculations based on the NRVS-determined geometric structure reproduce these MCD-derived data for SyrB2 and the trends in electronic spectra in going from $\left(\mathrm{TMG}_{3}\right.$ tren $) \mathrm{Fe}^{\mathrm{IV}}=\mathrm{O}$ to $\mathrm{SyrB} 2 \mathrm{Br}-\mathrm{Fe}^{\mathrm{IV}}=\mathrm{O}$. This allows a correlation of the spectroscopic data with the reactivity of the $\mathrm{SyrB} 2 \mathrm{Fe}^{\mathrm{IV}}=\mathrm{O}$ intermediate. The decrease in energy between the oxo-based $\pi$ and $\mathrm{Fe}-d_{X z / y z} \pi^{*}$ orbitals results in their larger CI admixture into the $d \pi^{*}$ $\rightarrow d \sigma^{*}$ LF states. This facilitates spin polarization in the $\mathrm{Fe}-$ oxo bond and increases its $\mathrm{Fe}^{\mathrm{III}}\left(S_{\mathrm{Fe}}=5 / 2\right)-$ oxyl character at the TS, compared to $\left(\mathrm{TMG}_{3}\right.$ tren $)-\mathrm{Fe}^{\mathrm{IV}}=\mathrm{O}$. Also, due to the $\pi$ anisotropy associated with the equatorial halide there are differences in strength and distortion of the Fe-oxo bond between the RCP $d_{x z} \pi^{*} \rightarrow d_{z^{2}} \sigma^{*}$ LF and LCP $d_{y z} \pi^{*} \rightarrow$ $d_{Z^{2}} \sigma^{*}$ LF states (Scheme 1B and C). The RCP $d_{X Z} \pi^{*} \rightarrow d_{Z^{2}} \sigma^{*}$ LF state, active in $\pi$ controlled $\mathrm{H}$ atom abstraction due to its orientation toward the $\mathrm{C}-\mathrm{H}$ bond, has a weaker, more distorted $\mathrm{Fe}-$ oxo bond. Thus, the $d_{X Z} \pi^{*}$ state becomes lower in energy at $\mathrm{Fe}-\mathrm{O}$ lengths relevant to the TS and hence has increased HAA reactivity in the direction of the substrate cavity (Scheme 1B and C).

Indeed, the $\pi$-channel for HAA by the $\mathrm{SyrB} 2 \mathrm{Fe}^{\mathrm{IV}}=\mathrm{O}$ intermediate (with the substrate $\mathrm{C}-\mathrm{H}$ bond perpendicular to the $\mathrm{Cl}-\mathrm{Fe}^{\mathrm{IV}}=\mathrm{O}$ plane) involves the $\mathrm{RCP} d_{X Z} \pi^{*}$ state and produces the $\mathrm{Cl}-\mathrm{Fe}^{\mathrm{III}}-\mathrm{OH} / \mathrm{L}-\mathrm{Thr}{ }^{\bullet}$ first intermediate. The comparison with the model complex $\left(\mathrm{TMG}_{3}\right.$ tren $) \mathrm{Fe}^{\mathrm{IV}}=\mathrm{O}$ reveals that the $\mathrm{Fe}^{\mathrm{IV}}=\mathrm{O}$ enzymatic intermediate is intrinsically more $\pi$-reactive due to its higher oxyl character and lower $\mathrm{Fe}$-oxo stretching frequency as observed by MCD spectroscopy.

\section{CONCLUSIONS}

This study used low-temperature MCD spectroscopy to define the electronic structure of the $S=2(\mathrm{SyrB} 2) \mathrm{Fe}^{\mathrm{IV}}=\mathrm{O}$ intermediate, for which the 5C TBP geometric structure was previously determined by NRVS. The VT MCD spectra, obtained for this SyrB2 $\mathrm{NHFe}^{\mathrm{IV}}=\mathrm{O}$ intermediate, show features that largely parallel those observed for the TBP $S=$ $2\left(\mathrm{TMG}_{3}\right.$ tren $) \mathrm{Fe}^{\mathrm{IV}}=\mathrm{O}$ model complex and provide significant insight into the low-lying $S=$ 2 excited states and the associated FMOs. The comparison of $\mathrm{SyrB} 2 \mathrm{Fe}^{\mathrm{IV}}=\mathrm{O}$ with $\left(\mathrm{TMG}_{3}\right.$ tren $)-\mathrm{Fe}^{\mathrm{IV}}=\mathrm{O}$ further allows evaluation of the oxo-Fe bonding and the lowsymmetry effects due to a halide on the nature of the FMOs (potential energy surfaces of low-lying $S=2$ states). This increased oxo character and $\pi$-anisotropy enhance the HAA reactivity along the direction of the substrate. The $\mathrm{H}$ atom abstraction pathway occurs through a $\pi$ channel leading to the TBP halide- $\mathrm{Fe}^{\mathrm{III}}(S=5 / 2)-\mathrm{OH}$ intermediate.

\section{Supplementary Material}

Refer to Web version on PubMed Central for supplementary material.

\section{Acknowledgments}

The project was supported by the National Institute of General Medical Sciences of the National Institutes of Health under Award Numbers R01GM040392 to E.I.S. and R01GM69657 to J.M.B. and C.K., by the National Science Foundation (MCB-642058 and CHE-724084 to J.M.B. and C.K.), and by the Grant Agency of the Czech Republic (Grant No. 15-10279Y to M.S.). M.S. is also grateful to the Rulíšek/Havlas groups for access to their computational clusters at IOCB in Prague and to the Czech Academy of Sciences for the Purkyně fellowship. 


\section{References}

1. Matthews ML, Neumann CS, Miles LA, Grove TL, Booker SJ, Krebs C, Walsh CT, Bollinger JM Jr. Proc Natl Acad Sci U S A. 2009; 106:17723-17728. [PubMed: 19815524]

2. Price JC, Barr EW, Tirupati B, Bollinger JM Jr, Krebs C. Biochemistry. 2003; 42:7497-7508. [PubMed: 12809506]

3. Riggs-Gelasco PJ, Price JC, Guyer RB, Brehm JH, Barr EW, Bollinger JM Jr, Krebs C. J Am Chem Soc. 2004; 126:8108-8109. [PubMed: 15225039]

4. Hoffart LM, Barr EW, Guyer RB, Bollinger JM Jr, Krebs C. Proc Natl Acad Sci U S A. 2006; 103:14738-14743. [PubMed: 17003127]

5. Galonić DP, Barr EW, Walsh CT, Bollinger JM Jr, Krebs C. Nat Chem Biol. 2007; 3:113-116. [PubMed: 17220900]

6. Fujimori DG, Barr EW, Matthews ML, Koch GM, Yonce JR, Walsh CT, Bollinger JM Jr, Krebs C, Riggs-Gelasco PJ. J Am Chem Soc. 2007; 129:13408-13409. [PubMed: 17939667]

7. Matthews ML, Krest CM, Barr EW, Vaillancourt FH, Walsh CT, Green MT, Krebs C, Bollinger JM Jr. Biochemistry. 2009; 48:4331-4343. [PubMed: 19245217]

8. Chang W, Guo Y, Wang C, Butch SE, Rosenzweig AC, Boal AK, Krebs C, Bollinger JM Jr. Science. 2014; 343:1140-1144. [PubMed: 24604200]

9. Eser BE, Barr EW, Frantom PA, Saleh L, Bollinger JM Jr, Krebs C, Fitzpatrick PF. J Am Chem Soc. 2007; 129:11334-11335. [PubMed: 17715926]

10. Panay AJ, Lee M, Krebs C, Bollinger JM Jr, Fitzpatrick PF. Biochemistry. 2011; 50:1928-1933. [PubMed: 21261288]

11. Blasiak LC, Vaillancourt FH, Walsh CT, Drennan CL. Nature. 2006; 440:368-371. [PubMed: 16541079]

12. Vaillancourt FH, Yin J, Walsh CT. Proc Natl Acad Sci U S A. 2005; 102:10111-10116. [PubMed: 16002467]

13. McDonald AR, Que L Jr. Coord Chem Rev. 2013; 257:414-428.

14. (a) Jackson TA, Rohde JU, Seo MS, Sastri CV, DeHont R, Ohta T, Kitagawa T, Münck E, Nam W, Que L Jr. J Am Chem Soc. 2008; 130:12394-12407. [PubMed: 18712873] (b) Martinho M, Banse F, Bartoli JF, Mattioli TA, Battioni P, Horner O, Bourcier S, Girerd JJ. Inorg Chem. 2005; 44:9592-9596. [PubMed: 16323949] (c) Kaizer J, Klinker EJ, Oh NY, Rohde JU, Song WJ, Stubna A, Kim J, Münck E, Nam W, Que L Jr. J Am Chem Soc. 2004; 126:472-473. [PubMed: 14719937] (d) England J, Bigelow JO, Van Heuvelen KM, Farquhar ER, Martinho M, Meier KK, Frisch JR, Münck E, Que L Jr. Chem Sci. 2014; 5:1204-1215. [PubMed: 24660055] (e) Comba P, Fukuzumi S, Kotani S, Wunderlich S. Angew Chem, Int Ed. 2010; 49:2622-2625.(f) Rohde J-U, Stubna A, Bominaar EL, Münck E, Nam W, Que L Jr. Inorg Chem. 2006; 45:6435-6445. [PubMed: 16878956] (g) Planas O, Clemancey M, Latour J-M, Company A, Costas M. Chem Commun. 2014; 50:10887-10890.

15. (a) England J, Guo Y, Farquhar ER, Young VG Jr, Münck E, Que L Jr. J Am Chem Soc. 2010; 132:8635-8644. [PubMed: 20568768] (b) Biswas AN, Puri M, Meier KK, Oloo WN, Rohde GT, Bominaar EL, Münck E, Que L Jr. J Am Chem Soc. 2015; 137:2428-2431. [PubMed: 25674662] (c) Lacy DC, Gupta R, Stone KL, Greaves J, Ziller JW, Hendrich MP, Borovik AS. J Am Chem Soc. 2010; 132:12188-12190. [PubMed: 20704272] (d) England J, Guo Y, Van Heuvelen KM, Cranswick MA, Rohde GT, Bominaar EL, Münck E, Que L Jr. J Am Chem Soc. 2011; 133:1188011883. [PubMed: 21739994]

16. Srnec M, Wong SD, England J, Que L Jr, Solomon EI. Proc Natl Acad Sci U S A. 2012; 109:14326-14331. [PubMed: 22908238]

17. Decker A, Rohde JU, Klinker EJ, Wong SD, Que L Jr, Solomon EI. J Am Chem Soc. 2007; 129:15983-15996. [PubMed: 18052249]

18. Solomon EI, Light KM, Liu LV, Srnec M, Wong SD. Acc Chem Res. 2013; 46:2725-2739. [PubMed: 24070107]

19. (a) Shaik S, Chen H, Janardanan D. Nat Chem. 2011; 3:19-27. [PubMed: 21160512] (b) Ye S, Neese F. Proc Natl Acad Sci U S A. 2011; 108:1228-1233. [PubMed: 21220293] (c) Neidig ML, Decker A, Choroba OW, Huang F, Kavana M, Moran GR, Spencer JB, Solomon EI. Proc Natl 
Acad Sci U S A. 2006; 103:12966-12973. [PubMed: 16920789] (d) Decker A, Clay MD, Solomon EI. J Inorg Biochem. 2006; 100:697-706. [PubMed: 16510189]

20. Wong SD, Srnec M, Matthews ML, Liu LV, Kwak Y, Park K, Bell CB III, Alp EE, Zhao J, Yoda Y, Kitao S, Seto M, Krebs C, Bollinger JM Jr, Solomon EI. Nature. 2013; 499:320-323. [PubMed: 23868262]

21. Diebold AR, Brown-Mashall CD, Neidig ML, Brownlee JM, Moran GR, Solomon EI. J Am Chem Soc. 2011; 133:18148-18160. [PubMed: 21981763]

22. (a) The PyMOL Molecular Graphics System, Version 1.5.0.4. Schrödinger, LLC; (b) Chovancova E, Pavelka A, Benes P, Strnad O, Brezovsky J, Kozlikova B, Gora A, Sustr V, Klvana M, Medek P, Biedermannova L, Sochor J, Damborsky J. PLoS Comput Biol. 2012; 8:e1002708. [PubMed: 23093919]

23. Ahlrichs R, Bär M, Häser M, Horn H, Kölmel C. Chem Phys Lett. 1989; 162:165-169.

24. Becke AD. Phys Rev A: At, Mol, Opt Phys. 1988; 38:3098-3100.

25. (a) Grimme S. J Comput Chem. 2004; 25:1463-1473. [PubMed: 15224390] (b) Grimme S. J Comput Chem. 2006; 27:1787-1799. [PubMed: 16955487]

26. (a) Roos BO, Taylor PR, Siegbahn PEM. Chem Phys. 1980; 48:157-173.(b) Siegbahn PEM, Almlöf J, Heiberg A, Roos BO. J Chem Phys. 1981; 74:2384-2396.

27. (a) Andersson K, Malmqvist P-Å, Roos BO, Sadlej AJ, Wolinski K. J Phys Chem. 1990; 94:54835488.(b) Andersson K, Malmqvist P-Å, Roos BO. J Chem Phys. 1992; 96:1218-1226.(c) Andersson K. Theor Chim Acta. 1995; 91:31-46.(d) Finley J, Malmqvist P-Å, Roos BO, SerranoAndrés L. Chem Phys Lett. 1998; 288:299-306.

28. Aquilante F, De Vico L, Ferré N, Ghigo G, Malmqvist P-Å, Neogrády P, Pedersen TB, Pitoňák M, Reiher M, Roos BO, Serrano-Andrés L, Urban M, Veryazov V, Lindh R. J Comput Chem. 2010; 31:224-247. [PubMed: 19499541]

29. (a) Douglas M, Kroll NM. Ann Phys (Amsterdam, Neth). 1974; 82:89-155.(b) Hess BA. Phys Rev A: At, Mol, Opt Phys. 1986; 33:3742-3748.(c) Jansen G, Hess BA. Phys Rev A: At, Mol, Opt Phys. 1989; 39:6016-6017.

30. Frisch, MJ., Trucks, GW., Schlegel, HB., Scuseria, GE., Robb, MA., Cheeseman, JR., Scalmani, G., Barone, V., Mennucci, B., Petersson, GA., Nakatsuji, H., Caricato, M., Li, X., Hratchian, HP., Izmaylov, AF., Bloino, J., Zheng, G., Sonnenberg, JL., Hada, M., Ehara, M., Toyota, K., Fukuda, R., Hasegawa, J., Ishida, M., Nakajima, T., Honda, Y., Kitao, O., Nakai, H., Vreven, T., Montgomery, JA., Jr, Peralta, JE., Ogliaro, F., Bearpark, M., Heyd, JJ., Brothers, E., Kudin, KN., Staroverov, VN., Kobayashi, R., Normand, J., Raghavachari, K., Rendell, A., Burant, JC., Iyengar, SS., Tomasi, J., Cossi, M., Rega, N., Millam, JM., Klene, M., Knox, JE., Cross, JB., Bakken, V., Adamo, C., Jaramillo, J., Gomperts, R., Stratmann, RE., Yazyev, O., Austin, AJ., Cammi, R., Pomelli, C., Ochterski, JW., Martin, RL., Morokuma, K., Zakrzewski, VG., Voth, GA., Salvador, P., Dannenberg, JJ., Dapprich, S., Daniels, AD., Farkas, Ö., Foresman, JB., Ortiz, JV., Cioslowski, J., Fox, DJ. Gaussian G09, revision D.01. Gaussian Inc; Wallingford, CT: 2009.

31. Malmqvist P-Å, Rendell A, Roos BO. J Phys Chem. 1990; 94:5477-5482.

32. Pierloot K. Mol Phys. 2003; 101:2083-2094.

33. (a) Hess BA, Marian CM, Wahlgren U, Gropen O. Chem Phys Lett. 1996; 251:365-371.(b) Schimmelpfennig, B. AMFI Program. University of Stockholm; Stockholm: 1996.

34. Malmqvist P-Å, Roos BO, Schimmelphennig B. Chem Phys Lett. 2002; 357:230-240.

35. (a) Roos BO, Andersson K. Chem Phys Lett. 1995; 245:215-243.(b) Forsberg N, Malmqvist P-Å. Chem Phys Lett. 1997; 274:196-204.

36. Neese F, Solomon EI. Inorg Chem. 1999; 38:1847-1865. [PubMed: 11670957]

37. Decker A, Rohde JU, Que L Jr, Solomon EI. J Am Chem Soc. 2004; 126:5378-5379. [PubMed: 15113207]

38. (a) Wayner DDM, Clark KB, Rauk A, Yu D, Armstrong DA. J Am Chem Soc. 1997; 119:89258932.(b) Burkey TJ, Castelhano AL, Griller D, Lossing FP. J Am Chem Soc. 1983; 105:47014703.

39. (a) Marcus RA. J Phys Chem. 1968; 72:891-899.(b) Gilmore K, Alabugin IV. Chem Rev. 2011; 111:6513-6556. [PubMed: 21861478] 


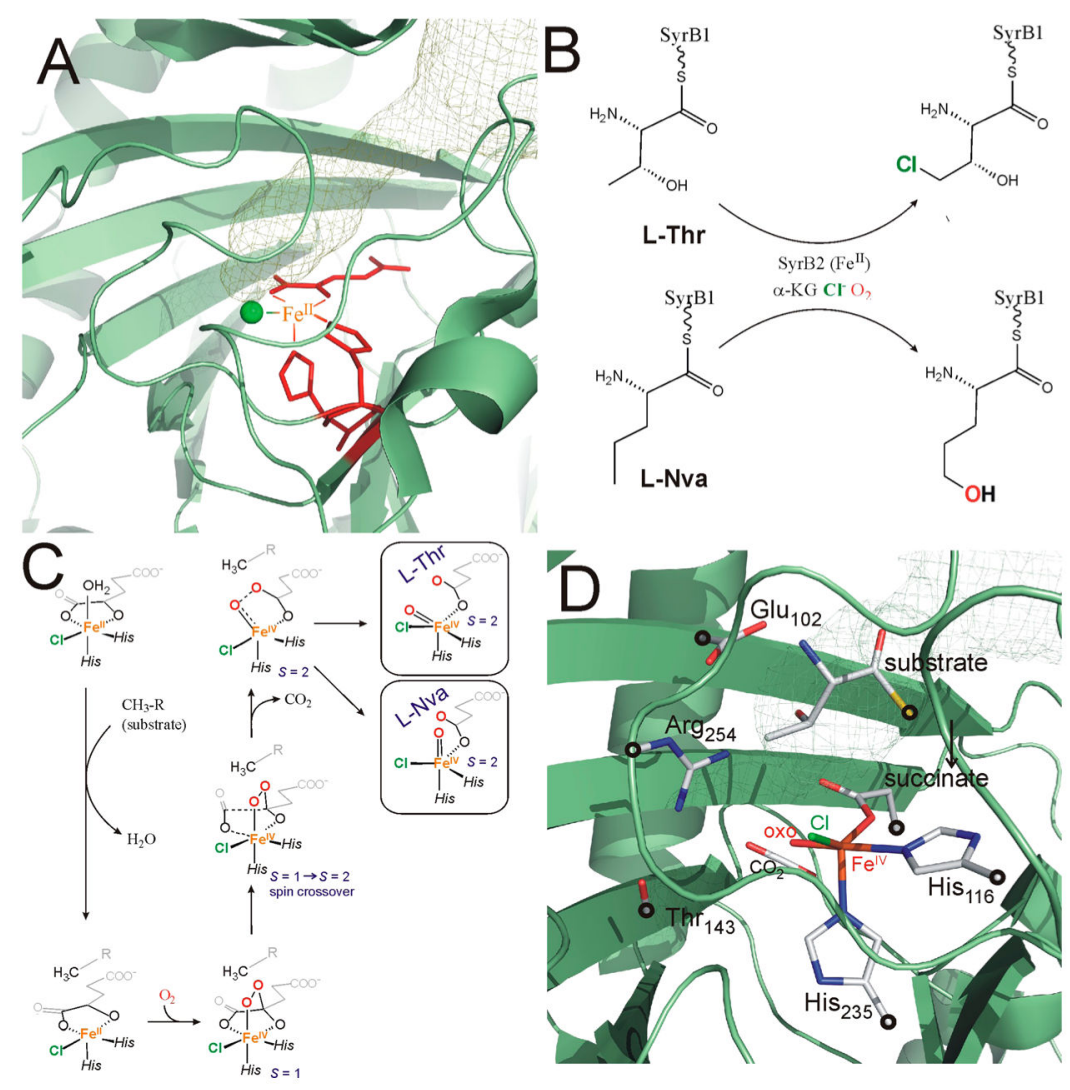

Figure 1.

(A) View of the $a$-ketoglutarate ( $a \mathrm{KG}$ )-bound $\mathrm{Fe}^{\mathrm{II}}$ center in SyrB2 (taken from 2FCT.pdb). ${ }^{11}$ Green sphere is the halide ligand, whereas red sticks correspond to the $a \mathrm{KG}$ and $\mathrm{His}_{116} / \mathrm{His}_{235}$ ligands; the mesh plot indicates the binding cavity for substrate as calculated by the Caver plugin in Pymol. ${ }^{22}$ (B) Halogenation of the native L-threonine substrate and hydroxylation of the non-native L-norvaline $\sim$ SyrB1 (L-Nva) substrate as defined in ref 1. (C) $\mathrm{O}_{2}$ activation pathway in SyrB2 in the presence of either L-Thr or L$\mathrm{Nva}$ as calculated in ref 20. (D) The cluster model of the $\mathrm{Fe}^{\mathrm{IV}}=\mathrm{O}$ intermediate (stick representation) with fixed atoms indicated by $\bigcirc$, overlaid with protein backbone. For clarity, water molecules and hydrogen atoms are not displayed. 


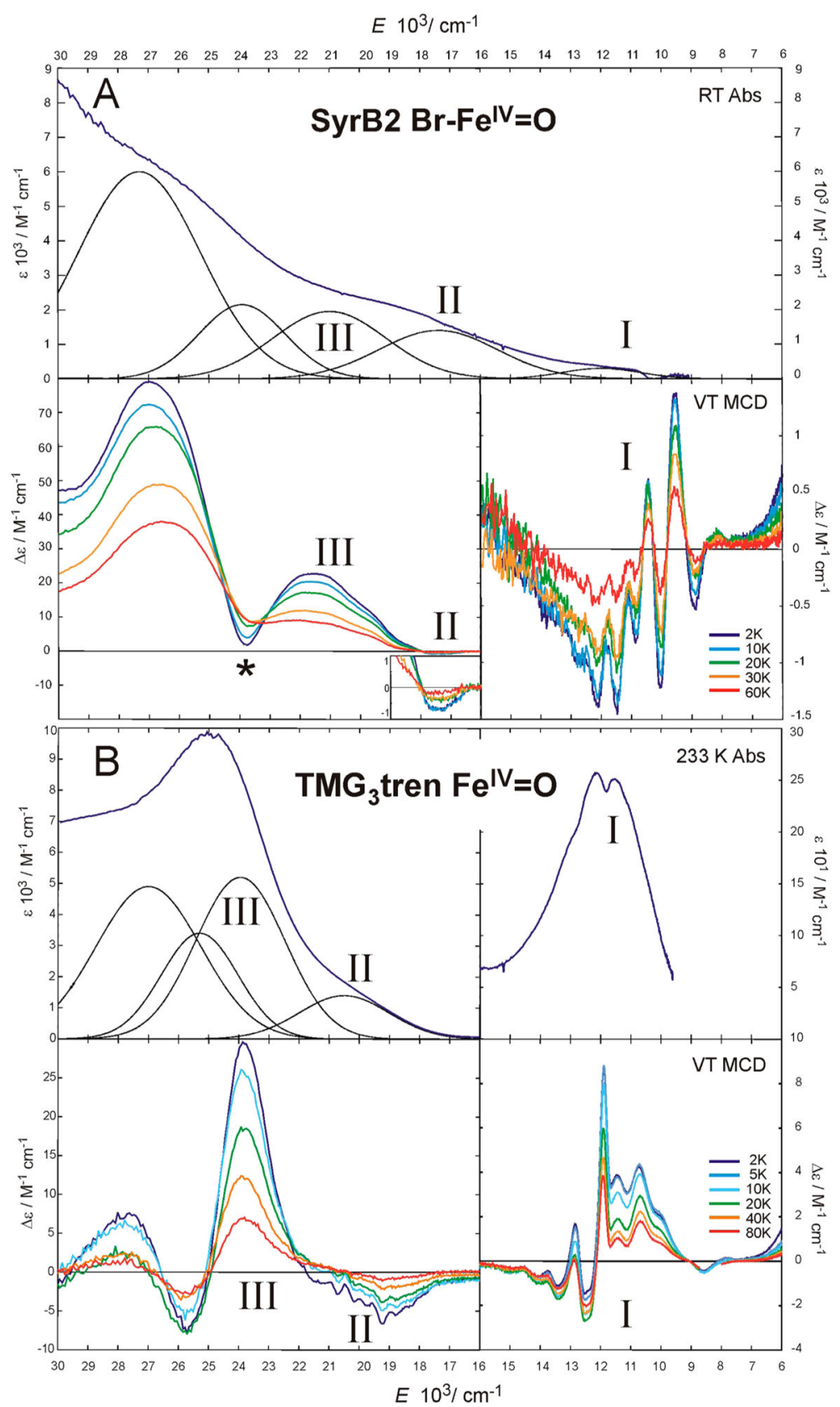

Figure 2.

(A) Absorption (top) and VT MCD spectra (bottom) of SyrB2 $\mathrm{Br}-\mathrm{Fe}^{\mathrm{IV}}=\mathrm{O}$. The * indicates a minor heme contaminant in the sample. (B) Absorption (top) and VT MCD spectra (bottom) of the $\left(\mathrm{TMG}_{3}\right.$ tren) $\mathrm{Fe}^{\mathrm{IV}}=\mathrm{O}$ model complex taken from ref 16 . Absorption spectra of both species were fitted by Gaussians through correlation with the MCD data. Three lowest-energy bands in all spectra are labeled I, II, and III. All MCD spectra were measured at a magnetic field of $7 \mathrm{~T}$. 

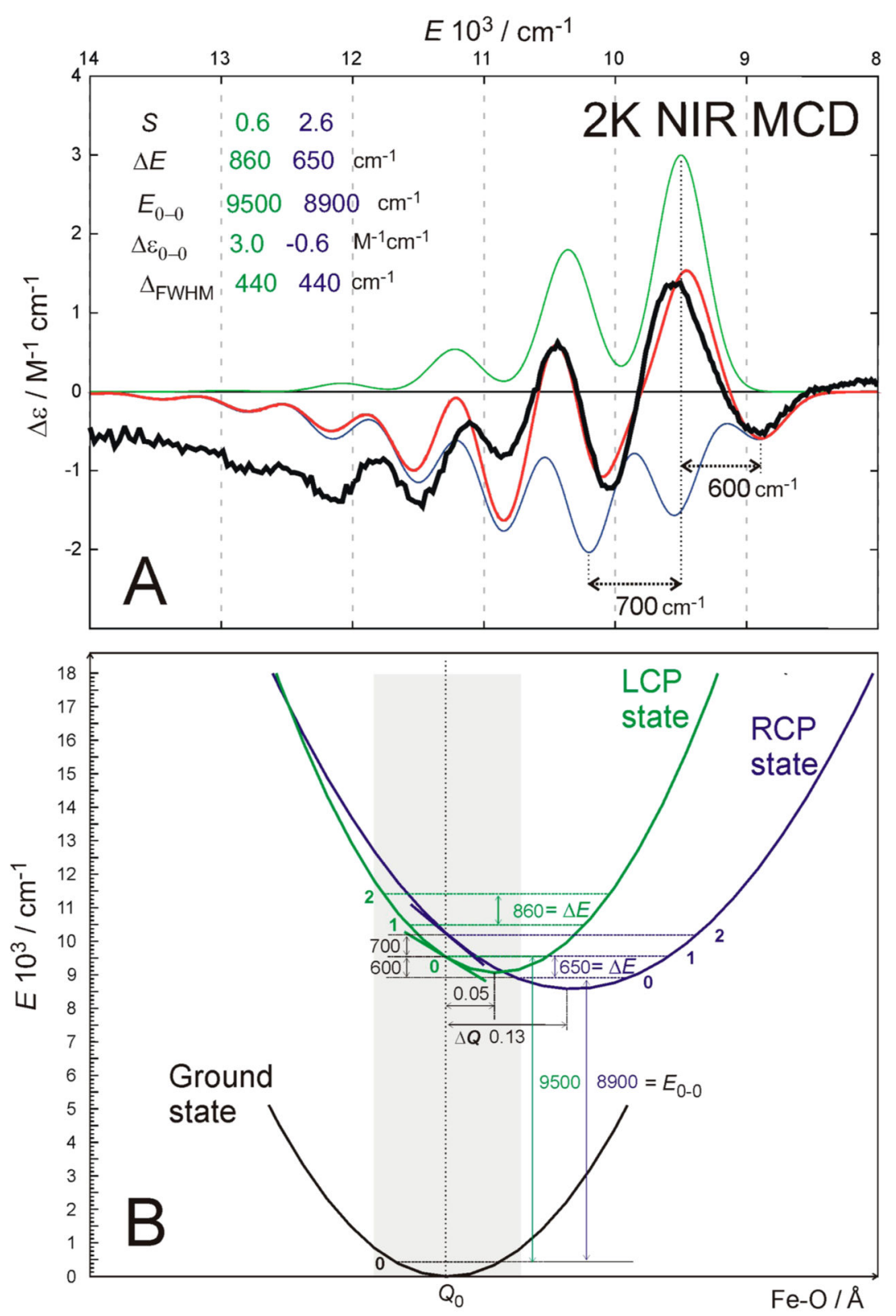

Figure 3.

(A) The NIR pseudo-A term (black) fitted according to the eq 1 by two FC vibronic progressions (the LCP component in green, the RCP component in blue and their sum in red). Values of FC progression parameters, defined in section 2.3, are also displayed. The value of $600 \mathrm{~cm}^{-1}$ corresponds to the separation between the zero-phonon energies of the blue vs green FC progression (i.e., separation of the ground vibrational levels of the RCP vs LCP state). The value of $700 \mathrm{~cm}^{-1}$ corresponds to the energy splitting between the most intense vibronic peaks of the green vs blue FC progression, reflecting the LCP vs RCP state splitting at the ground-state equilibrium. Both values are also indicated in Figure 3B. (B) Parabolic PES representations obtained from FC fits as calculated using the eqs 2 and 3 . The 
$\mathrm{Fe}-$ oxo stretching frequency $\left(800 \mathrm{~cm}^{-1}\right)$ is assumed for the ground-state parabola. The excited-state distortions, $\Delta Q$ s, were obtained from eq 2 . 


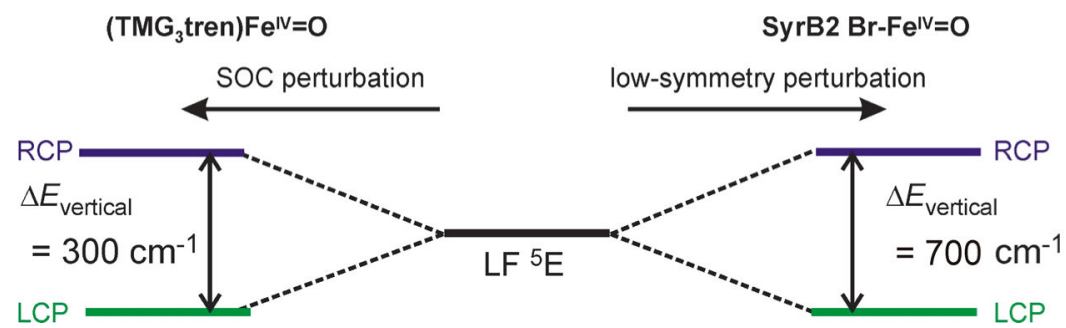

Figure 4.

Two different origins of the pseudo-A term in the MCD spectra of $S=2$ TBP ferryl species: low-symmetry splitting of $\mathrm{LF}^{5} \mathrm{E}$ state in $\mathrm{Br}-\mathrm{Fe}^{\mathrm{IV}}=\mathrm{O}$ (right) vs SOC splitting of $\mathrm{LF}^{5} \mathrm{E}$ in

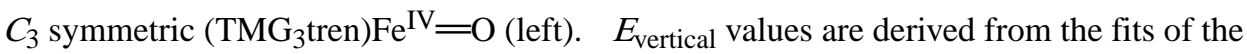
vibronically resolved pseudo-A term features using two FC progressions. 

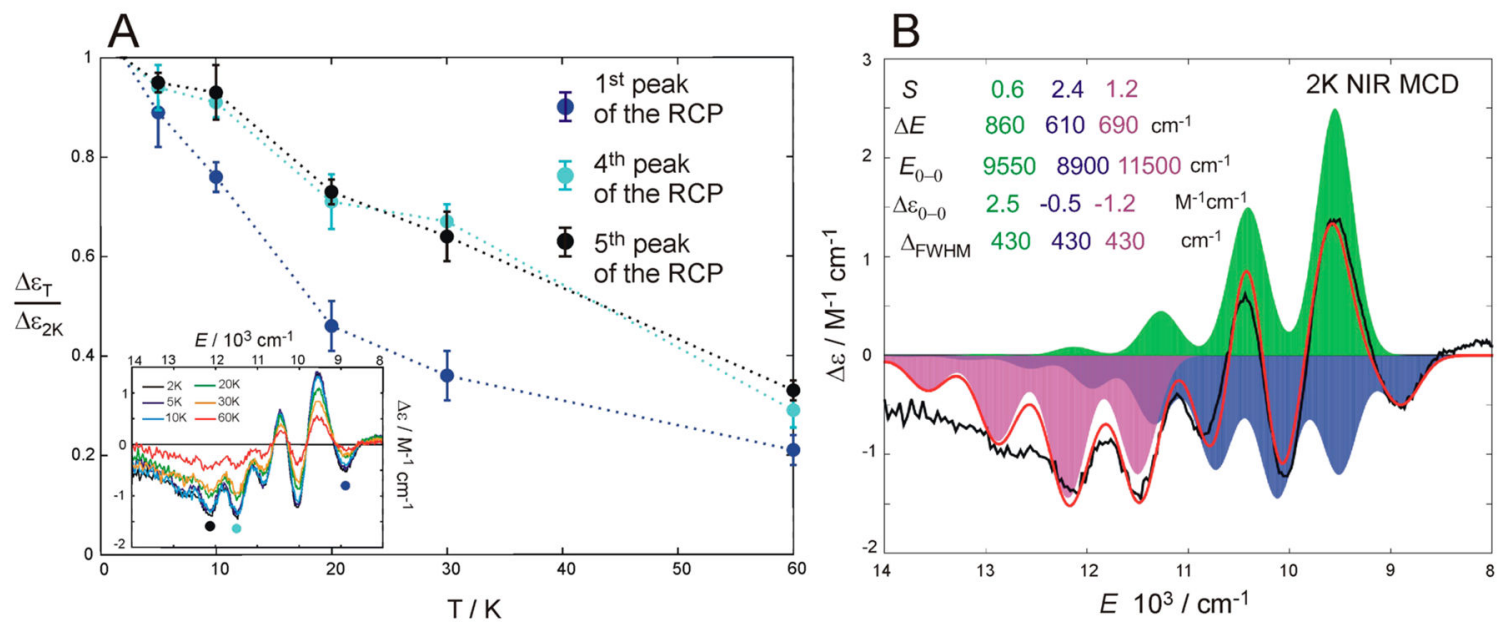

Figure 5.

(A) MCD intensity of the first, fourth and the fifth RCP peak measured at different temperatures $T\left(\Delta \varepsilon_{\mathrm{T}}\right)$ and normalized to its MCD intensity at $2 \mathrm{~K}\left(\Delta \varepsilon_{2 \mathrm{~K}}\right)$. (B) Fit of the NIR pseudo-A term by three FC vibronic progressions. 


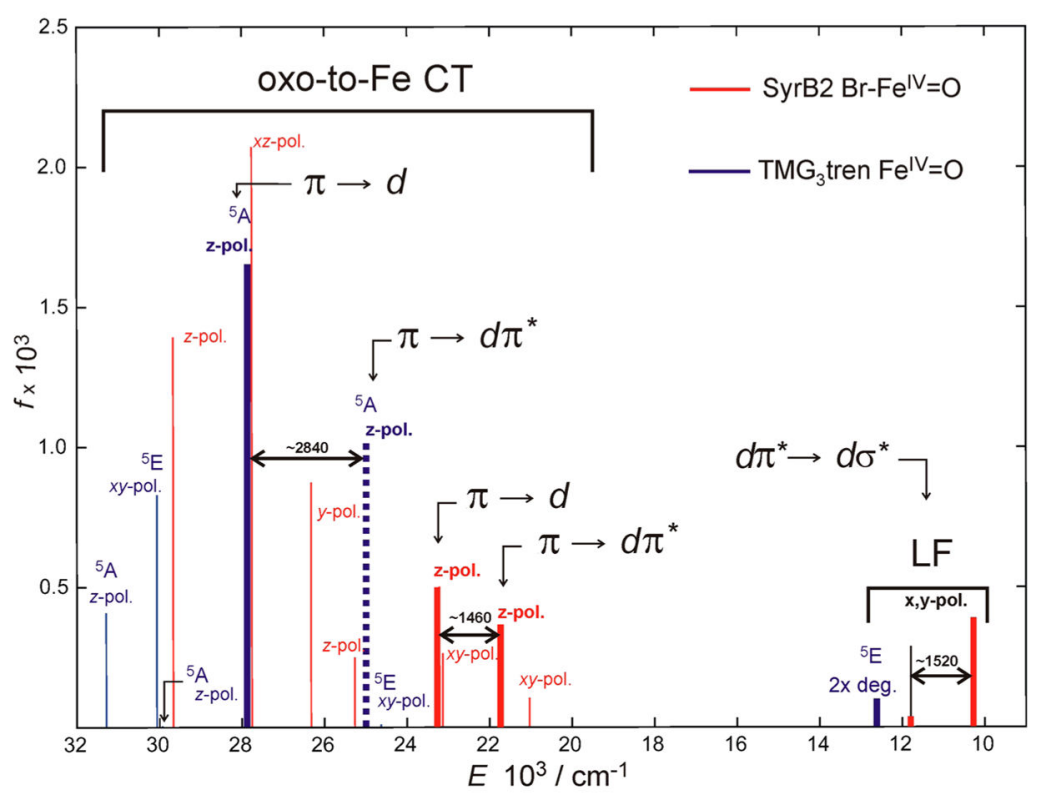

Figure 6.

RASSCF electronic spectra of the SyrB2 $\mathrm{Br}-\mathrm{Fe}^{\mathrm{IV}}=\mathrm{O}$ (red) and $\left(\mathrm{TMG}_{3}\right.$ tren) $\mathrm{Fe}^{\mathrm{IV}}=\mathrm{O}$ species (blue). Heights of solid lines correspond to oscillator strengths of electronic transitions. Dotted line indicates the position of the transition with a near-to-zero oscillator strength. Polarizations and assignments of transitions are also shown. The thick lines are transitions that correspond to experimental bands I, II, and III from Figure 2. For the orbitals, see Figure 8. 


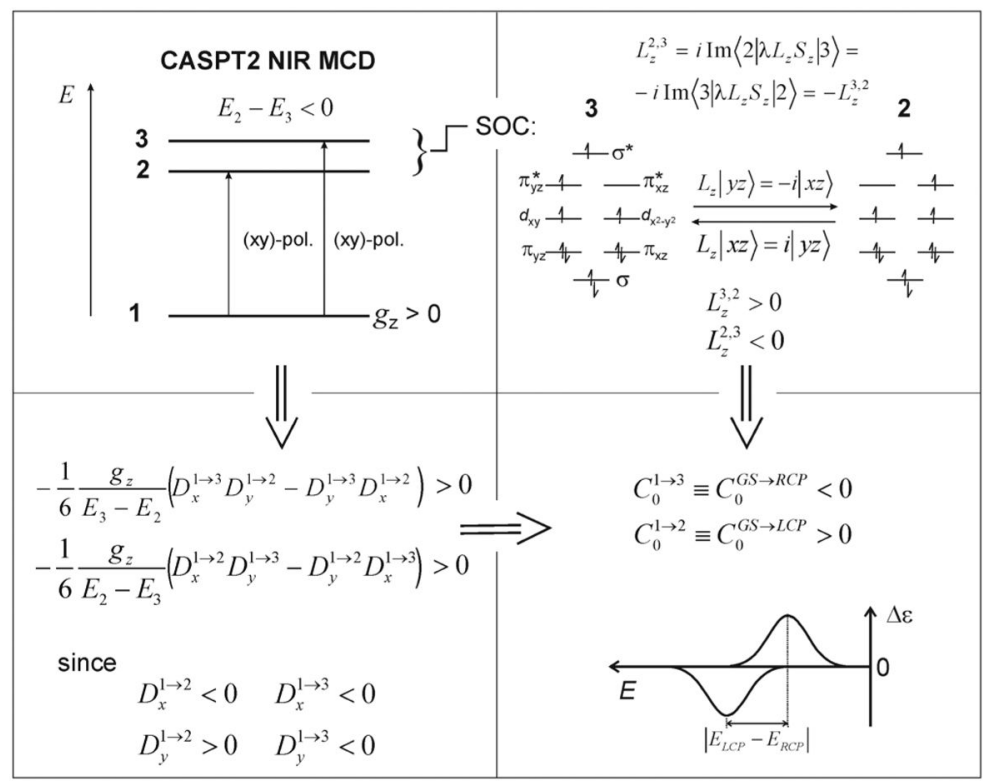

Figure 7.

MCD transitions to two lowest $S=2$ excited states (labeled in this figure as states 2 and 3 ) give rise to a pair of positively and negatively signed $\mathrm{C}$ terms forming a derivative-shaped pseudo-A term with negative component at higher energies. Signs of the $\mathrm{C}$ terms $\left(C_{0}^{1 \rightarrow 2}\right.$ and $C_{0}^{1 \rightarrow 3}$ ) are determined by using eqs 5 and 6 . The energies $(E)$, transition dipole moments $(D)$, and SOC matrix elements $\left(L_{Z}\right)$ listed in the figure were obtained using CASSCF/ CASPT2/SO-CASSI calculations. 

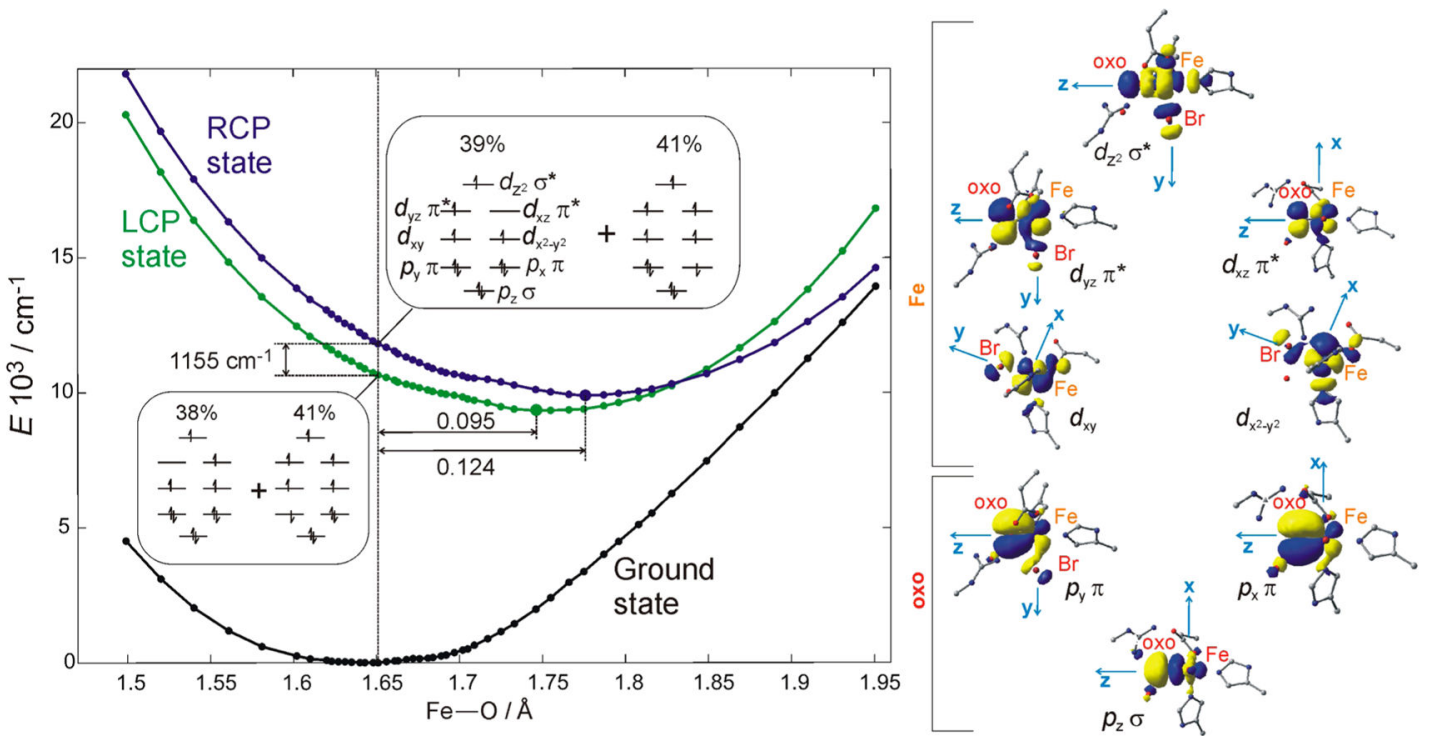

Figure 8.

CASPT2 PESs of three lowest $S=2$ states along the Fe-O coordinate (left). Two main configurations contributing to wave function character of each excited state at the groundstate equilibrium are also displayed. The corresponding frontier molecular orbitals are depicted in the right panel. 


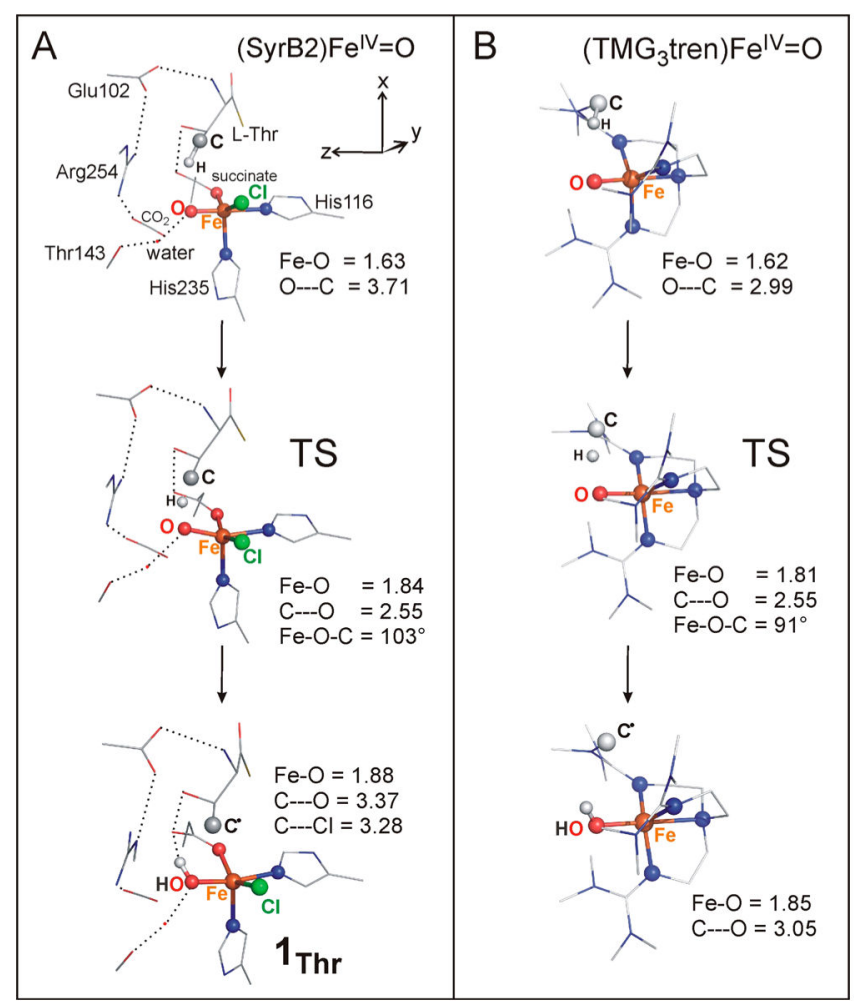

Figure 9.

$\pi$ Trajectory for $\mathrm{H}$ atom abstraction from the native substrate L-Thr in SyrB2 (A) and from the chelate of the $S=2$ model complex (B). For the products, the high-spin $(S=5 / 2) \mathrm{Fe}^{\mathrm{III}}$ center is weakly antiferromagnetically coupled to the $\mathrm{C}^{\bullet}$ of the substrate. Key geometric parameters (in $\AA$ ) are included. The Cartesian coordinates of all structures are shown in the Supporting Information. For clarity, the H atoms are not visualized. Relative energies, enthapies, and free energies of the structures (calculated as described in section 2.5) are given in Table 2 and Table $\mathrm{S} 2$. 


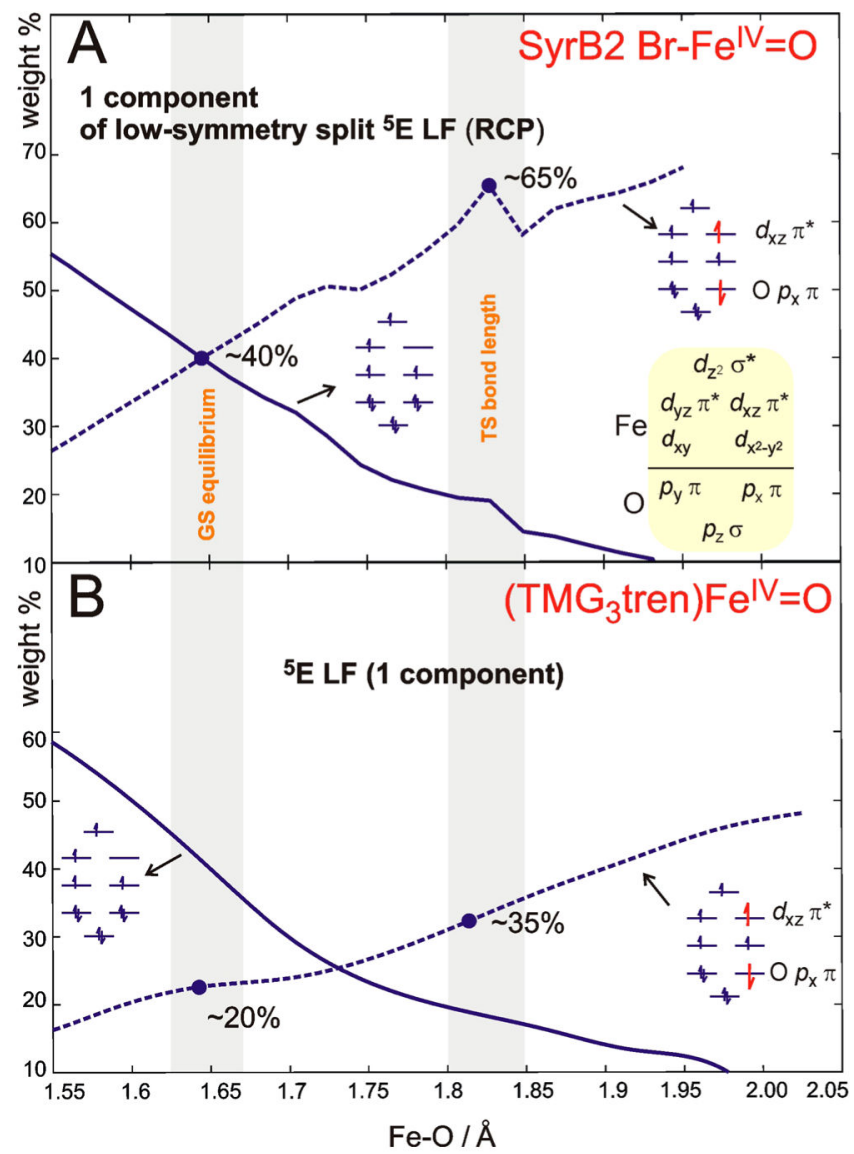

Figure 10.

Evolution of the dominant electronic configurations contributing to the CASPT2 wave function character of the lowest-energy excited LF state in $(\mathrm{SyrB} 2) \mathrm{Fe}^{\mathrm{IV}}=\mathrm{O}(\mathrm{A})$ and (TMG3tren) $-\mathrm{Fe}^{\mathrm{IV}}=\mathrm{O}(\mathrm{B})$. Only one component of the LF state (associated with the substrate-oriented $d_{X Z} \pi^{*}$ FMO) is shown in both cases. Orbitals associated with the configurations are displayed in Figure 8 (left panel therein). The GS equilibrium and TS Fe$\mathrm{O}$ lengths are indicated by a gray bars. 


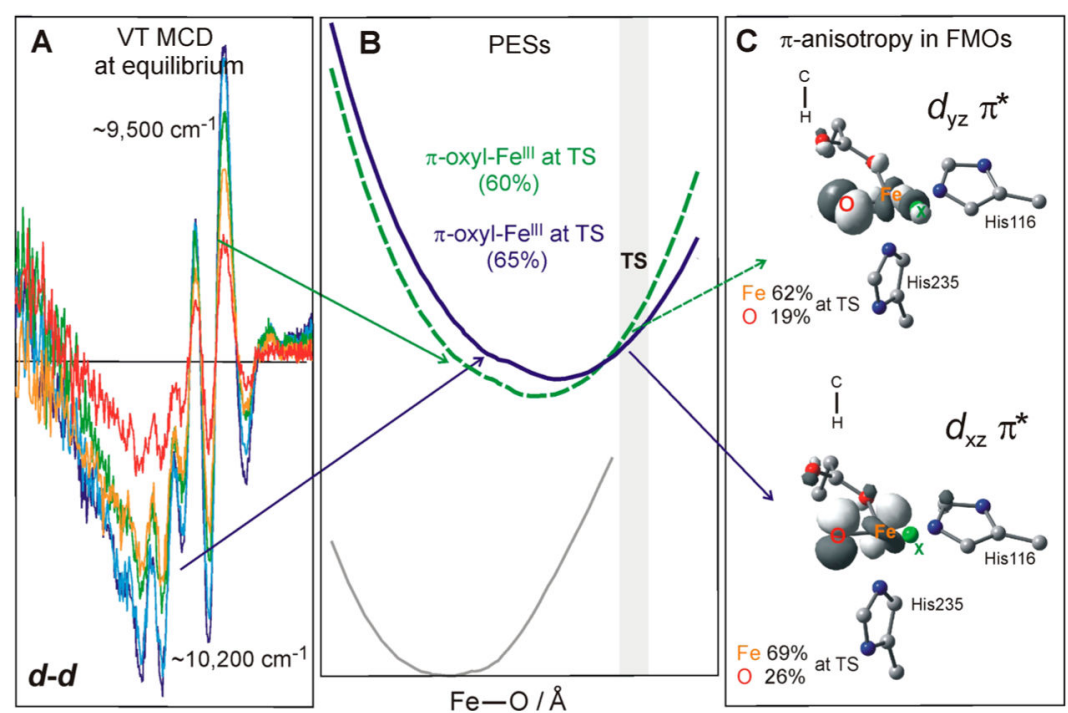

\section{Scheme 1.}

Vibronically Resolved VT MCD Spectra (A) Describe the Electronic Structure of the Halide $-\mathrm{Fe}^{\mathrm{IV}}=\mathrm{O}$ Active Site at the Equilibrium Geometry As Well As a Difference in the Shape of PESs of the Two Lowest Lf Excited States (B) That Is Associated with Anisotropy of $\pi$ FMOs; This $\pi$-Anisotropy Leads to a Larger Oxyl-Fe ${ }^{\mathrm{III}}$ Character in the Substrate-Oriented Direction at the TS Fe-O Lengths (C) and Results in a Lower-Energy $d_{X Z} \pi^{*}$ FMO That Is Perpendicular to the Fe-Halide Bond and Well-Oriented for H-Atom Abstraction from the Substrate C-H Bond 


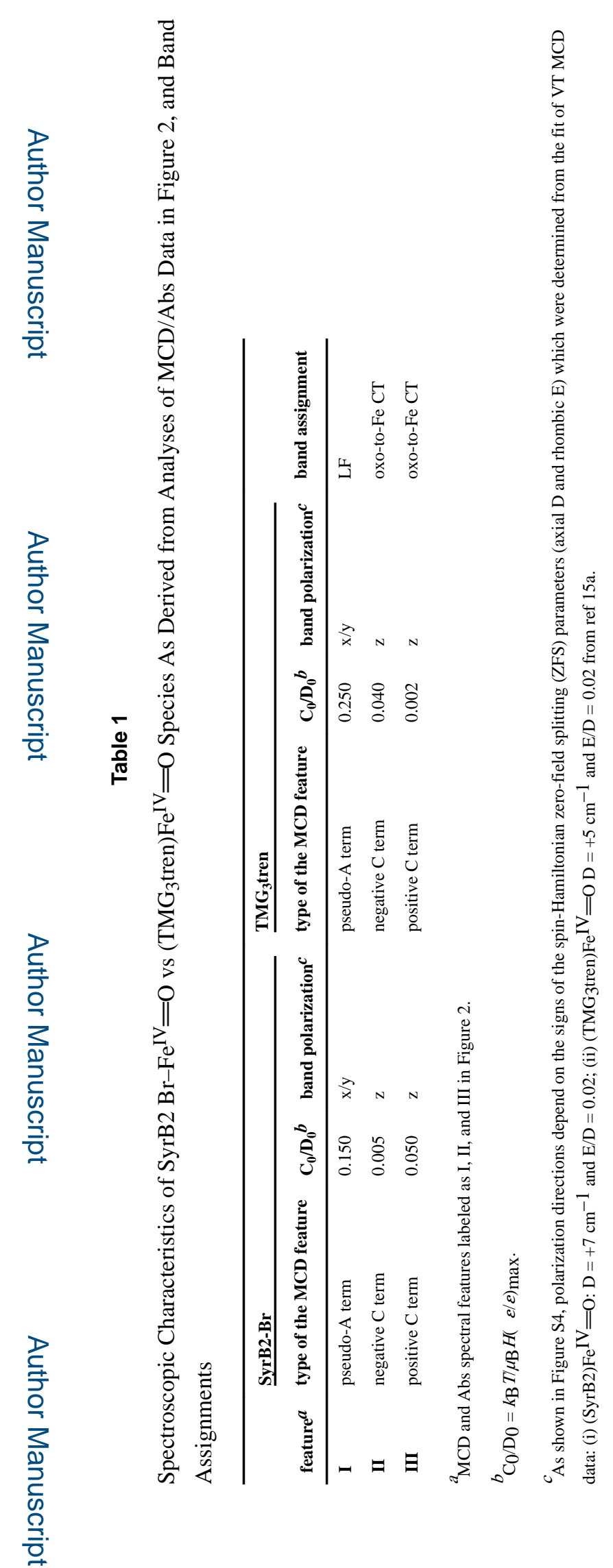

J Am Chem Soc. Author manuscript; available in PMC 2017 April 20. 


\section{Table 2}

(Activation/Reaction) Potential Energies, Enthalpies and Free Energies of the $\pi\left(S_{\mathrm{Fe}}{ }^{\mathrm{III}}=5 / 2\right)$-Controlled HAtom Abstraction from the Native Substrate by the $(\mathrm{SyrB} 2) \mathrm{Fe}^{\mathrm{IV}}=\mathrm{O}$ and $\left(\mathrm{TMG}_{3}\right.$ tren $) \mathrm{Fe}^{\mathrm{IV}}=\mathrm{O}$ Species; the Intrinsic Reaction Barriers Are Also Given (All Values Are in $\mathrm{kcal} \mathrm{mol}^{-1}$ )

\begin{tabular}{|c|c|c|c|}
\hline system & $\Delta E^{\sharp} \not \Delta H H^{\prime} \Delta G^{\neq}$ & $\Delta E^{\circ} / \Delta H^{\circ} / \Delta G^{\circ}$ & $\Delta E_{\mathrm{intr}}^{z^{\prime}} / \Delta H_{\mathrm{intr}}^{z^{\prime}} / \Delta G_{\mathrm{intr}}^{z_{1}}$ \\
\hline$(\mathrm{SyrB} 2) \mathrm{Fe}^{\mathrm{IV}}=\mathrm{O}^{a}$ & $23.1^{c} / 18.9 / 19.8$ & $3.9 / 0.6 / 2.3$ & $21.1 / 18.6 / 18.6$ \\
\hline$\left(\mathrm{TMG}_{3} \operatorname{tren}\right) \mathrm{Fe}^{\mathrm{IV}}=\mathrm{O}^{b}$ & $25.3 / 21.6 / 21.4$ & $5.9 / 3.2 / 0.5$ & $22.3 / 20.3 / 21.6$ \\
\hline
\end{tabular}

${ }^{a}$ Within the cluster model from Figure 9, the second-shell residue Arg254 appears to sterically destabilize the transition state/product relative to the reactant by 3-4 kcal mol${ }^{-1}$. Here, the DFT results are presented for the cluster model in the absence of this Arg residue. For the energetics of the Arg-including cluster model of the active site from Figure 9, see Table S1.

${ }^{b}$ Calculated at the same level of theory as SyrB2 (described in Computational Details) but with a dielectric constant of $\mathcal{E}=35.7$ mimicking the solvation effect of acetonitrile.

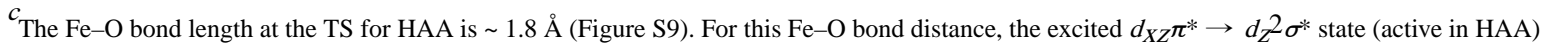
is calculated at the CASPT2 level of theory to lie $\sim 10000 \mathrm{~cm}^{-1}\left(\sim 28 \mathrm{kcal} \mathrm{mol}^{-1}\right)$ above the ground state minimum (Figure 8). This energy difference includes (i) the ground-state $\mathrm{Fe}-\mathrm{O}$ distortion that is associated with the energy increase by $\sim 5000 \mathrm{~cm}^{-1}\left(\sim 14 \mathrm{kcal} \mathrm{mol}^{-1}\right)$ and (ii) the excitation from the ground state to the $d_{X Z} \pi^{*} \rightarrow d_{\mathrm{Z} 2} \sigma^{*}$ state that requires an additional amount of $\sim 14 \mathrm{kcal} / \mathrm{mol}$. The difference of $\sim 28 \mathrm{kcal}$ $\mathrm{mol}^{-1}$ taken from Figure 8 relative to the DFT-calculated $\pi$-controlled HAA barrier of $\sim 23 \mathrm{kcal} \mathrm{mol}^{-1}$ ( $\Delta E^{\ddagger}$ for comparison to PES calculations) reflects the interaction of the $\mathrm{Fe}^{\mathrm{IV}}=\mathrm{O}$ moiety with the substrate $\mathrm{C}-\mathrm{H}$ bond. 